\title{
Multicasting Technique to Enhance the Performance of DSR Routing Protocol Using Various Performance Metrics under Different Traffic Conditions in Mobile Ad hoc Networks
}

\author{
Kulwinder Kaur ${ }^{1}$ and Simar Preet Singh ${ }^{2}$ \\ ${ }^{1}$ Research Scholar CSE Department DAV University Jalandhar Punjab \\ ${ }^{2}$ Assistant Professor CSE Department DAV University Jalandhar Punjab \\ ${ }^{1}$ kulwinder.lubana9991@gmail.com, ${ }^{2}$ er.simarpreetsingh@gmail.com
}

\begin{abstract}
Development of an efficient routing protocol is one of the major key challenges in the design of Mobile ad hoc networks (MANETs). DSR reactive routing protocol is the most preferred routing protocol in MANETs due its capability to store already discovered routes in the node's cache. In DSR routing protocol, in order to find a route to the destination, the source node broadcasts RREQ (Route Request) packets to its all neighbouring nodes and this broadcasting of RREQ packets results in more overhead. In this paper, we propose a multicasting technique to enhance the performance of DSR routing protocol and to reduce the broadcasting overhead. The performance analysis of DSR and enhanced DSR (EDSR) is carried out by varying number of nodes under different traffic conditions with different packet sizes and different network sizes. Also the performance analysis of DSR and enhanced DSR is carried out under different propagation models. The performance metrics used for the performance analysis of DSR and Enhanced DSR are Packet Delivery Ratio (PDR), Average End-to-End Delay, Throughput, Normalized Routing Load (NRL) and Energy Consumption.
\end{abstract}

Keywords: MANETs, DSR, EDSR, TCP, CBR, FTP, UDP, Two ray ground, Shadowing, PDR, Delay, Throughput, NRL, Energy Consumption

\section{Introduction}

A mobile ad hoc network (MANETs) is a collection of nodes that can communicate with each other directly or through intermediate nodes without any predefined infrastructure. The nodes in this network are mobile and self- configuring. The topology of MANET keeps on changing due to mobility of nodes. MANETs use multihop routing rather than single-hop routing to deliver packets to the destination [1].In MANETs, all the nodes may not be within the transmission range of other nodes, so, nodes are required to forward network traffic on behalf of other nodes. The process of forwarding network traffic from source to destination is known as routing. Consider the Figure 1; if node $\mathrm{S}$ sends data to node $\mathrm{D}$, which is three hops away, the data traffic will reach its destination only if nodes A and B forward it. 


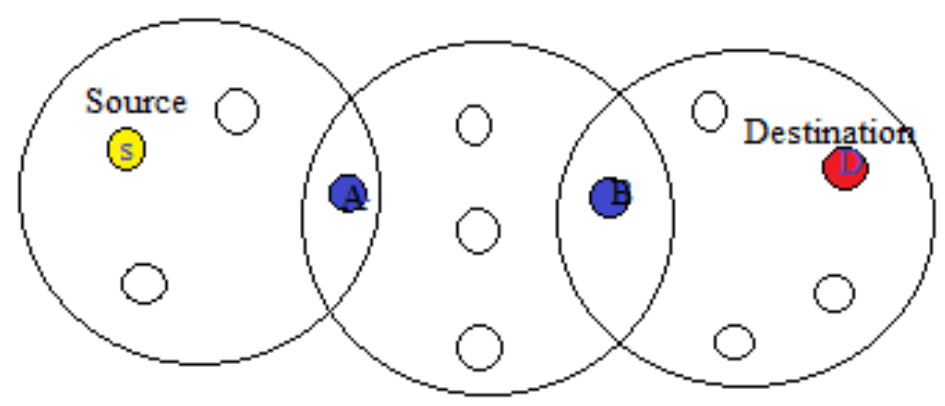

Figure 1. Multihop Routing

One of the key challenges in the design of ad hoc network is the development of an efficient routing protocol that can provide high quality communication among mobile nodes [2]. Routing in MANETs is done by routing protocols. MANETs routing protocols are broadly classified into two categories: Proactive routing protocols and Reactive routing protocols. In Proactive routing protocols, each node in the network maintains a routing table and the information in the routing tables are updated periodically [3]. This routing information is used by every node to store the location information of other nodes in the network and this information is used to move data among different nodes in the network. When a source node has to send a packet to the destination node, the route to that destination is available immediately. This proactive routing protocol is also called table driven routing protocol. In Reactive routing protocols, nodes maintain their routing tables on an on-demand basis [3].If a source node has to send a packet to destination node, firstly the route to the destination node is determined and then a connection is established between these nodes.

This paper has been structured as follows. Section 2 gives an overview of DSR routing protocol and its broadcasting routing technique of forwarding the RREQ packets. Section 3 describes an enhanced DSR routing protocol and how multicasting technique can be achieved. Section 4 presents simulation methodology and describes the various performance metrics that are used to evaluate the performance of DSR and enhanced DSR routing protocol. Section 5 presents the analysis of simulation results and finally, in Section 6 we present our conclusion.

\section{Dynamic Source Routing Protocol (DSR)}

DSR is an on-demand protocol that uses source routing method [4].In this protocol, the nodes maintains route cache and the route cache is updated when a new node is known. Routing in DSR is done in two phases: Route discovery and Route maintenance. When a source node has to send a data packet to the destination node, it first checks route to the destination in the route cache. If the route to the destination is present in the route cache then the source node sends the data packet to the destination and if it is not present in the route cache it broadcasts RREQ packet. When a link breakage in an active route is detected, a RRER (Route Error) message is used to notify other nodes about the loss of the link. The source removes any route using this link from its cache. 


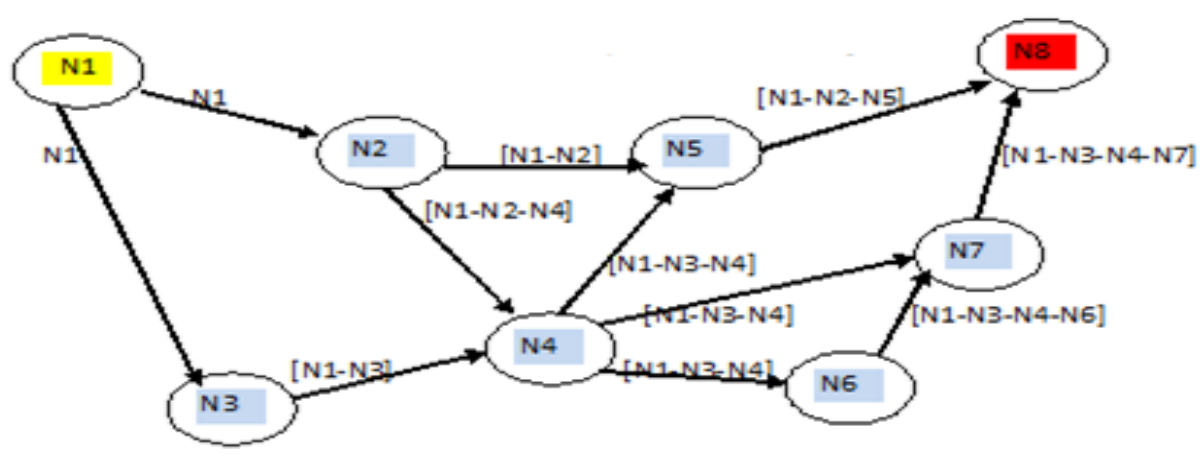

a) Route Discovery

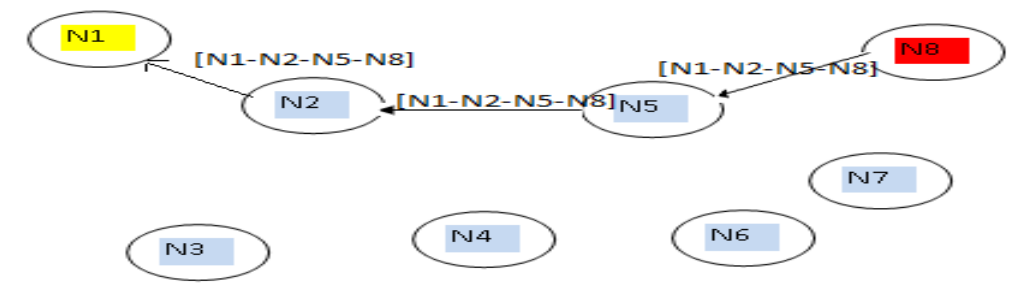

b) Route reply with the route record

Figure 2. DSR Routing Operations

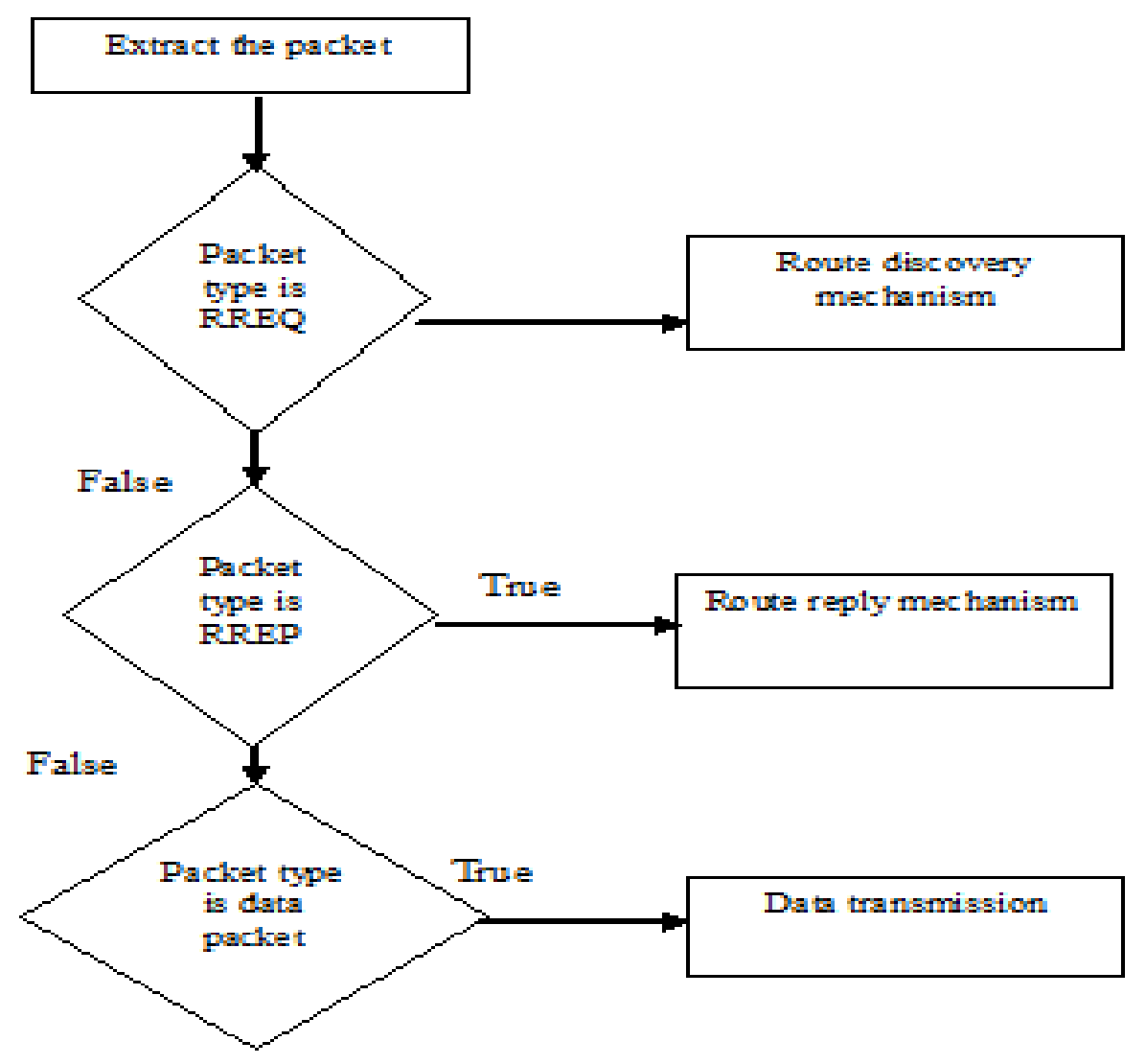

Flow Chart of Dynamic Source Routing Protocol (DSR) [5] 

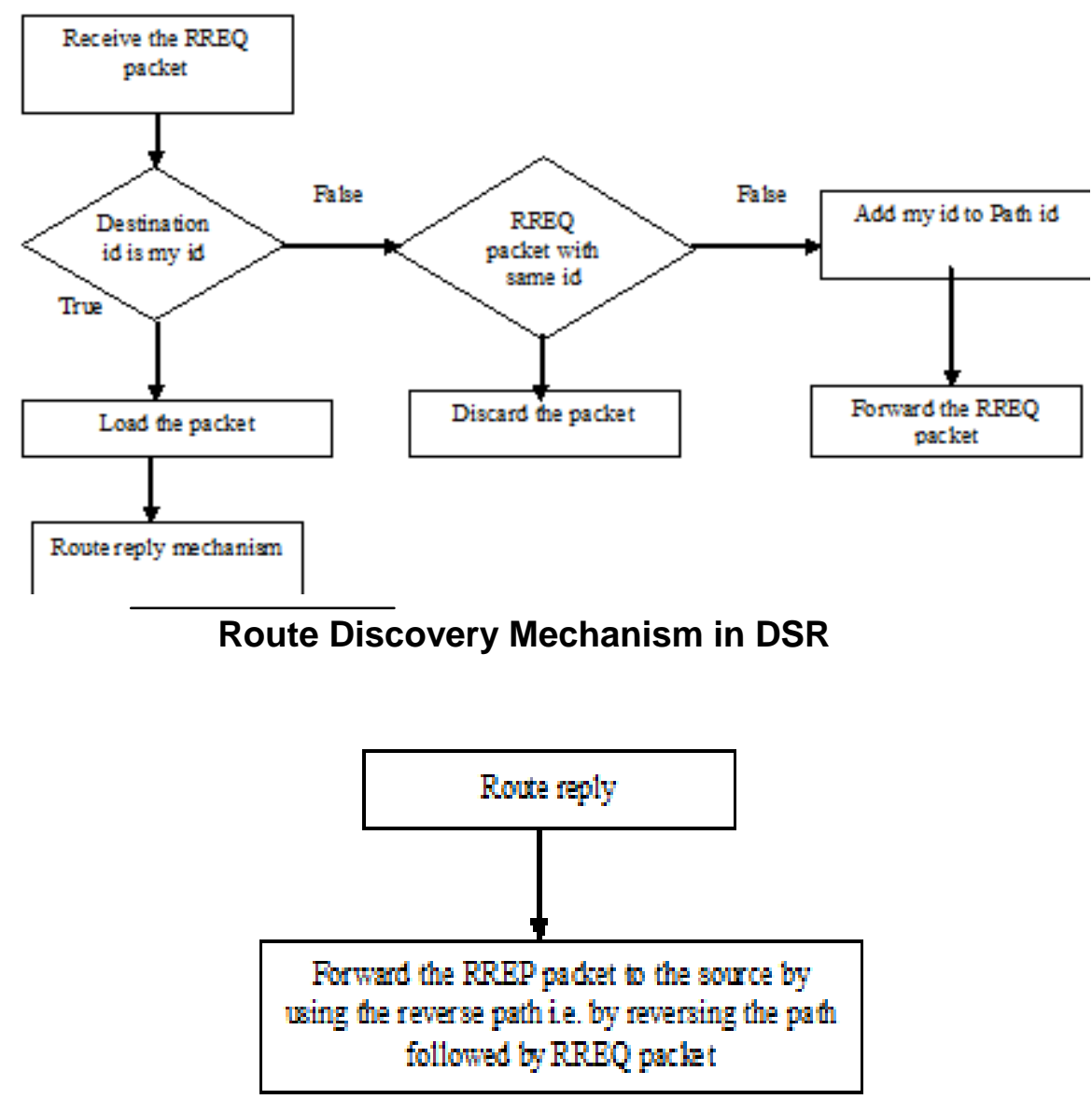

Route Reply Mechanism in DSR

\section{Enhanced DSR (EDSR)}

In EDSR, a multicasting technique of RREQ packets has been proposed. In EDSR, when a node receives a RREQ packet, it finds all of its neighboring nodes from its neighbor table in the route cache. It selects those nodes from the neighbor table whose id is not present in the RREQ packet and then it forwards RREQ packet to those selected nodes. 


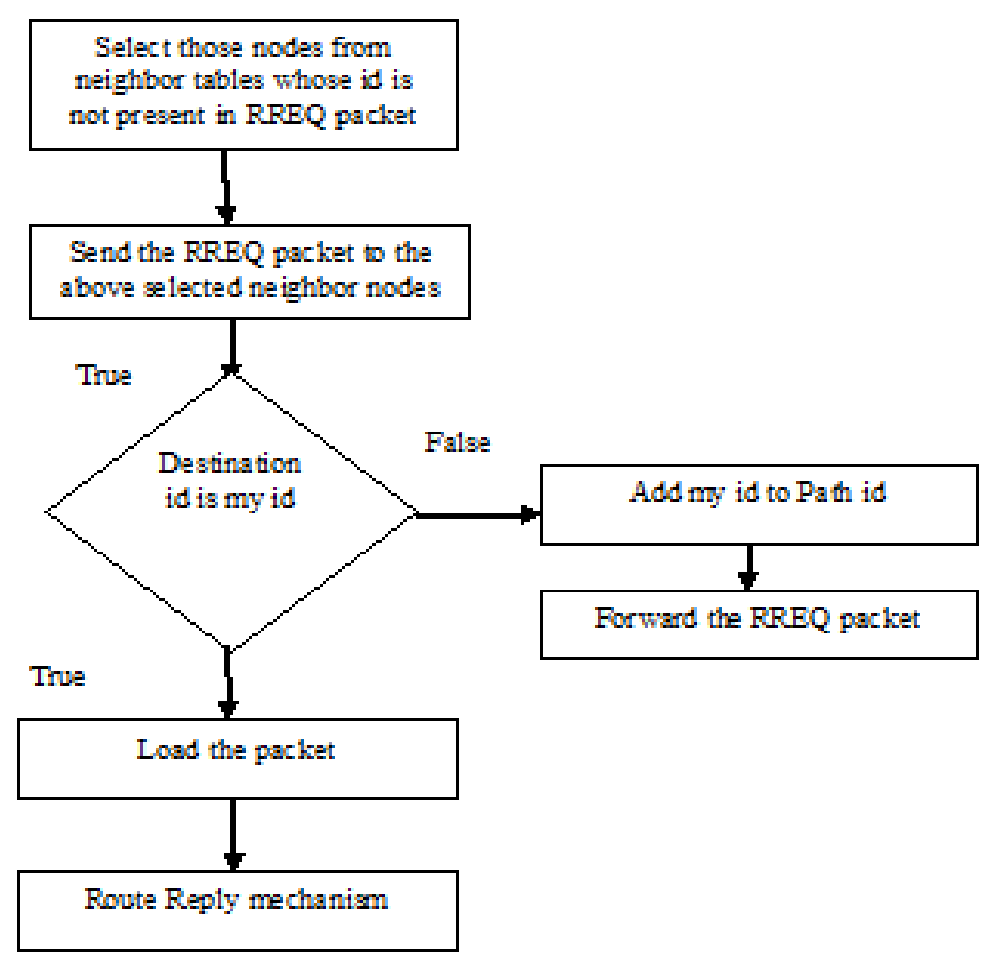

Route Discovery mechanism in EDSR

\section{Simulation Methodology and Performance Metrics}

\subsection{Simulation Setup}

The Simulation was performed using the Network Simulator 2 (NS-2) [6]. The Simulation Parameters used for the performance analysis of DSR and Enhanced DSR routing protocols are presented in Table 1.

Table 1. Simulation Parameters and Values

\begin{tabular}{|l|l|}
\hline Simulation Parameters & Value \\
\hline Simulator & NS-2 \\
\hline Simulation Area & $1000 \mathrm{~m} * 1000 \mathrm{~m}, 1500 \mathrm{~m} * 1500 \mathrm{~m}$ \\
\hline Routing Protocols & DSR, Enhanced DSR \\
\hline MAC Protocol & IEEE 802.11 \\
\hline Mobile Nodes & $25,50,75,100,125$ \\
\hline Packet Size & 512 bytes and 1000 bytes \\
\hline Antenna Type & Omni Antenna \\
\hline Propagation Models & Two Ray Ground, Shadowing \\
\hline Traffic Type & TCP,CBR,FTP,UDP \\
\hline
\end{tabular}

\subsection{Traffic Conditions}

The traffic conditions used for the performance analysis of DSR and EDSR are as follows:

4.2.1. Transmission Control Protocol (TCP): TCP is a connection oriented and reliable transport protocol. TCP is used in both fixed and mobile wireless networks.TCP uses 
acknowledgement to ensure reliable data transfer between source and destination. If a source fails to receive acknowledgement from the destination within a specific period of time, then the packet is assumed to be lost and TCP is required to retransmit that packet again [7].

4.2.2. Constant Bit Rate (CBR): CBR is non-connection oriented traffic model that sends traffic at a constant bit rate. CBR is tailored for any type of data for which end systems require predictable response time and a static amount of bandwidth to be continuously available for the lifetime of the connection [8].

4.2.3. File Transfer Protocol (FTP) [9]: FTP provides the facility to transport the files. The performance of FTP protocol may get affected by the size of file as it is related to occupied network and server resource. The FTP protocol can be realized and deployed easily.

4.2.4. User Datagram Protocol (UDP): UDP protocol is used for the real-time delivery of data packets both in wired and wireless networks [10].

\subsection{Propagation Models}

When a packet is received, the propagation model determines the attenuation between the transmitter and receiver and predicts the received signal strength. The propagation models used to compute the signal power received by the receiver are as follows:

4.3.1. Two Ray Ground Model: Two Ray Ground Model has both the line of sight (LOS) and the ground reflection path [11].

4.3.2. Shadowing Model: Shadowing Model considers the obstructions between a transmitter and a receiver. In the real environment, the obstruction is due to the tall buildings or striking of the signal with any obstacles during the propagation [11].

\subsection{Performance Metrics}

The Performance metrics used for performance analysis of the DSR and enhanced DSR routing protocol are as follows:

4.4.1. Packet Delivery Ratio (PDR) [12]: Packet Delivery Ratio is defined as the ratio of the number of data packets received by the destination to the number of data packets sent by the source. The greater the PDR is, better is the performance of routing protocol. Packet Delivery Ratio is computed as follows:

$$
\text { Packet Delivery Ratio }=\frac{\text { Total number of packets received by the destination }}{\text { Total number of packets send by the source }} * 100
$$

4.4.2. Average End-to-End Delay [13]: Average End-to-End Delay is defined as the average time taken by data packets to traverse the network and reach the destination. It includes all the possible delays like processing delay, queuing delay, transmission delay and propagation delay. Average End-to-End delay is computed as follows:

$$
\text { Average End }- \text { to }- \text { End Delay }=\frac{\text { Delay Sum }}{\text { Received Packets }}
$$

4.4.3. Throughput: Throughput is defined as the number of packets that are successfully transmitted to their destination per unit time. It is measured in bits per second (bps). Higher throughput is better. 
4.4.4. Normalized Routing Load (NRL): NRL is defined as the ratio of the total number of routing packets sent over the network to the total number of data packets received by the destination. NRL is computed as follows [14]:

$$
N R L=\frac{\text { Routing Control Packets }}{\text { Data Packets Delivered }}
$$

4.4.5. Energy Consumption: Energy Consumption of a node in MANETs is due to the transmission and the reception of data or control packet [15].

\section{Analysis of Simulation Results}

5.1. Performance Analysis of DSR And EDSR by Varying Number Of Nodes Under TCP And CBR Traffic Condition With 512 Bytes And 1000 Bytes Packet Size

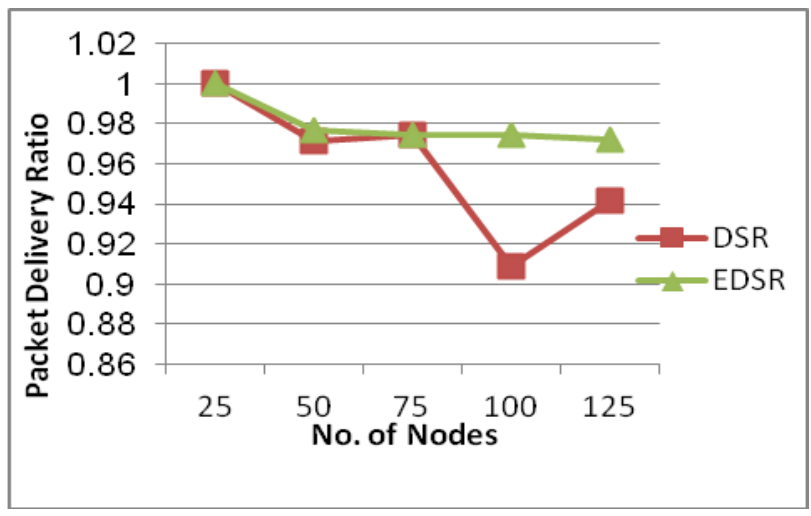

(a)Packet Delivery Ratio (512 bytes)

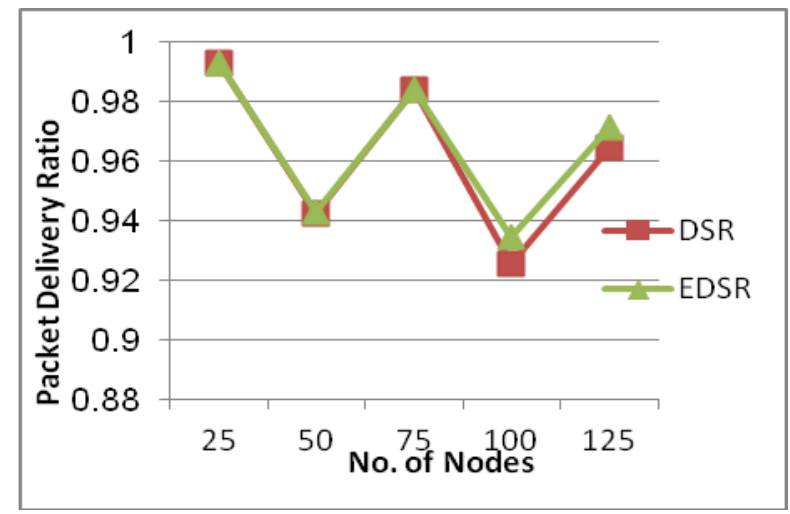

(b)Packet Delivery Ratio (1000 bytes)

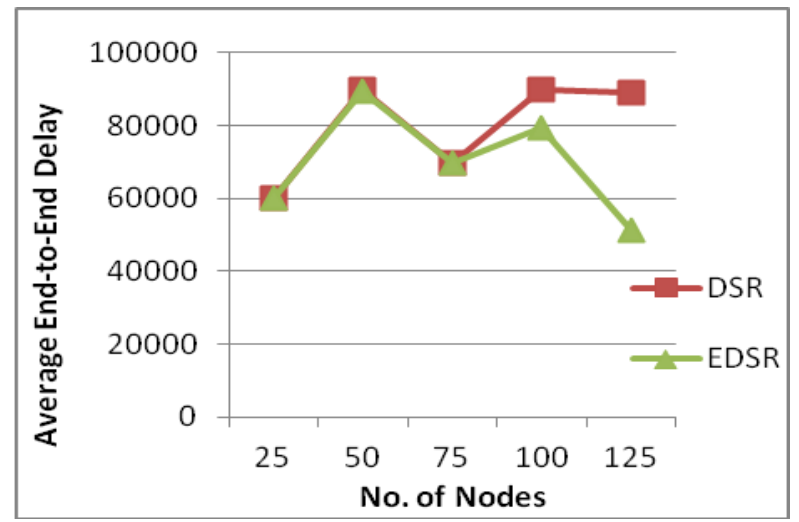

(c) Average End-to-end Delay (512 bytes) 
International Journal of Future Generation Communication and Networking Online Vol. 9, No. 4, (2016)

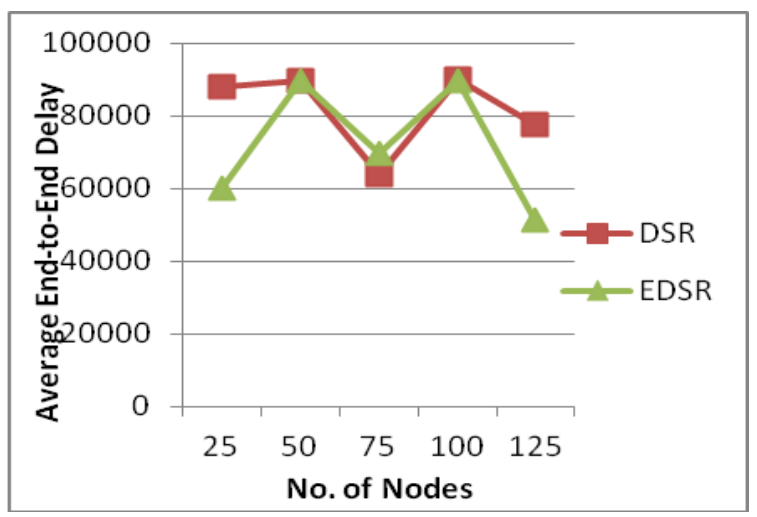

(d) Average End-to-End Delay (1000 bytes)

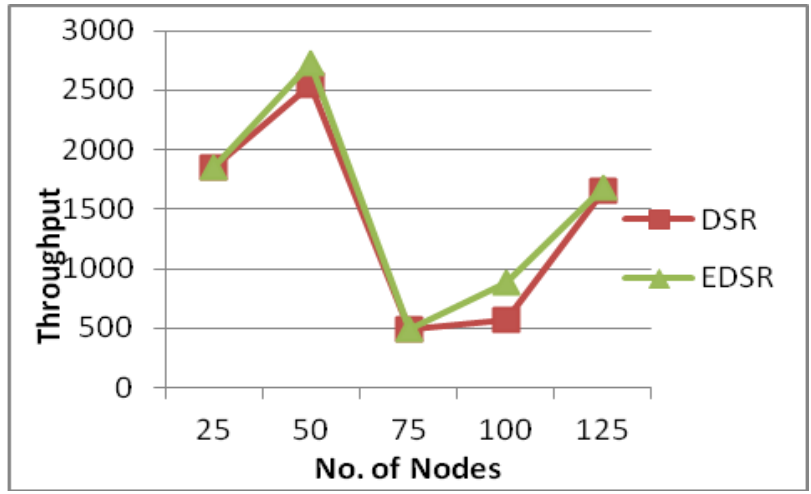

(e) Throughput (512 bytes)

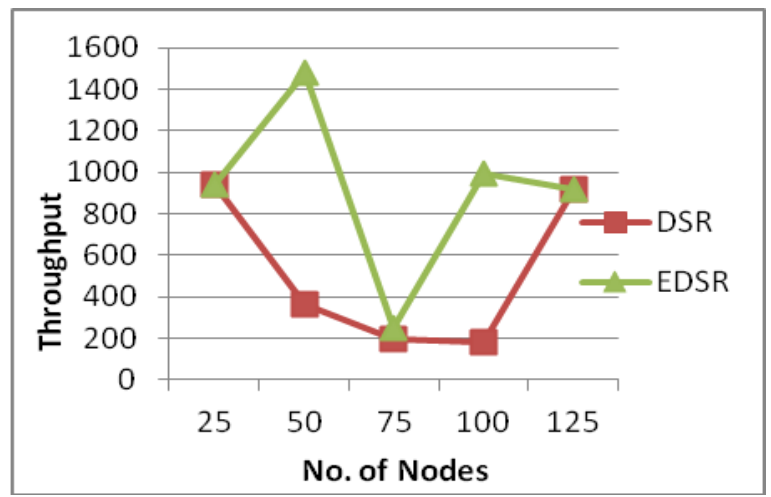

(f) Throughput (1000 bytes)

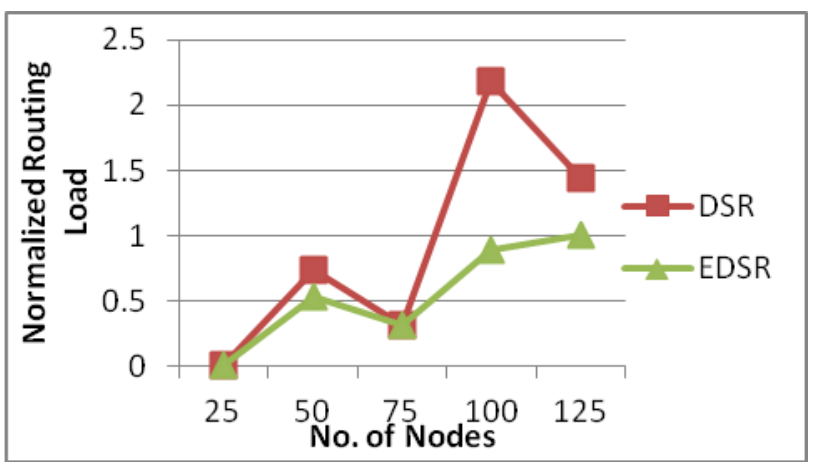

(g) Normalized Routing Load (512 bytes) 


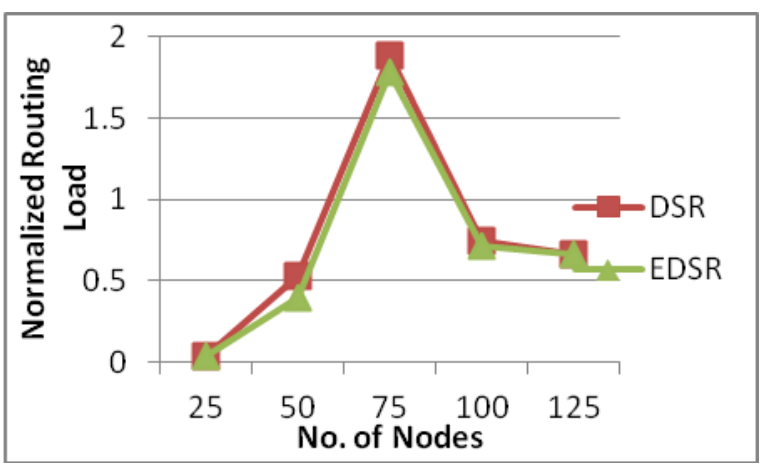

(h) Normalized Routing Load (1000 bytes)

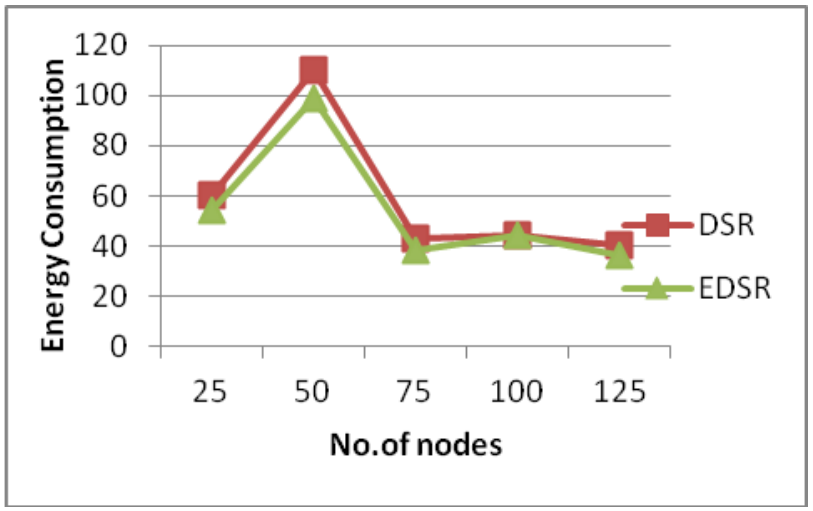

(i) Energy Consumption (512 bytes)

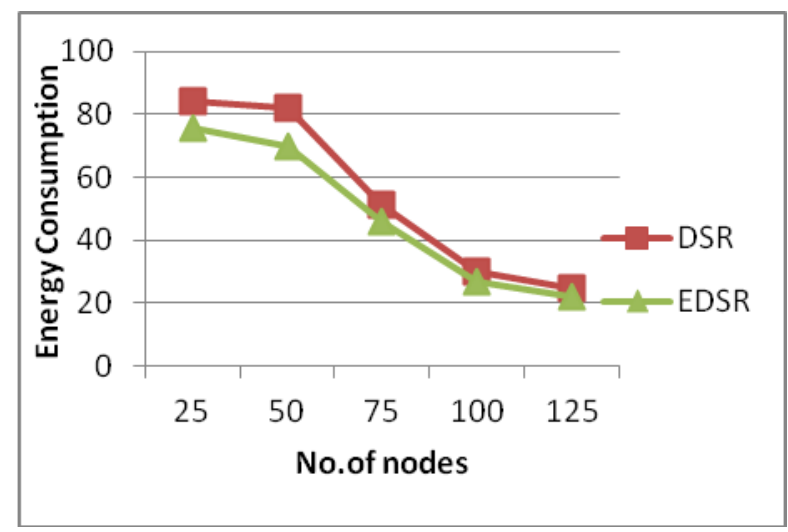

(j) Energy Consumption (1000 bytes)

Figure 3. Performance Analysis under TCP and CBR Traffic Condition by varying Number of Nodes and Different Packet Sizes (a) Variation of Packet Delivery Ratio (512 bytes) (b) Variation of Packet Delivery Ratio (1000 bytes)

(c) Variation of Average End-to-End Delay (512 bytes) (d) Variation of Average End-to-End Delay (1000 bytes) (e) Variation of Throughput (512 bytes) (f) Variation of Throughput (1000 bytes) (g) Variation of Normalized Routing Load (512 bytes) (h) Variation of Normalized Routing Load (1000 bytes) (i) Variation of Energy Consumption (512 bytes) (j) Variation of Energy Consumption (1000 bytes) 


\subsubsection{Performance Analysis by varying Number of Nodes}

The performance analysis is done by varying number of nodes i.e. $25,50,75,100$ and 125.The performance analysis of DSR and EDSR routing protocols is carried out under different traffic conditions with different packet sizes. Figure 3 shows the performance analysis of DSR and EDSR routing protocols under TCP and CBR traffic condition by varying number of nodes with different packet size. In Figure 3 (a) the variation of Packet Delivery Ratio is shown with 512 bytes packet size. The Packet Delivery Ratio in EDSR is more than the DSR routing protocol. In Figure3 (b) the variation of Packet Delivery Ratio is shown with 1000 bytes packet size. The Packet Delivery Ratio in EDSR is better than in DSR. In Figure3 (c) the variation of Average End-to-End Delay is shown with 512 bytes packet size. The Average End-to-End Delay in EDSR is less than in DSR routing protocol and decreases as the number of nodes increases in EDSR routing protocol. In Figure3 (d) the variation of Average End-to-End Delay is shown with 1000 bytes packet size. Again the Average End-to-End Delay in EDSR is less than in DSR routing protocol. Figure 3 (e) shows the variation of throughput with 512 bytes packet size. The throughput in EDSR is more than in DSR routing protocol and increases as the number of nodes increases in EDSR. Figure3 (f) shows the variation of throughput with 1000 bytes packet size. Throughput is better in EDSR than DSR routing protocol. Figure3 (g) shows the variation of Normalized Routing Load with 512 bytes packet size. Normalized Routing Load is less in EDSR than in DSR routing protocol. Figure3 (h) shows the variation of Normalized Routing Load with 1000 bytes packet size. Normalized Routing Load is less in EDSR than in DSR routing protocol and decreases as number of nodes increases in EDSR routing protocol. Figure3 (i) shows the variation of Energy Consumption with 512 bytes packet size. Energy Consumption is less in EDSR than in DSR routing protocol. Figure 3 (j) shows the variation of Energy Consumption with 1000 bytes packet size. Energy Consumption is less in EDSR than in DSR routing protocol and decreases as number of nodes increases in EDSR routing protocol.

5.2. Performance Analysis of DSR and EDSR by Varying Number of Nodes Under TCP and FTP Traffic Condition with 512 Bytes and 1000 Bytes Packet Size

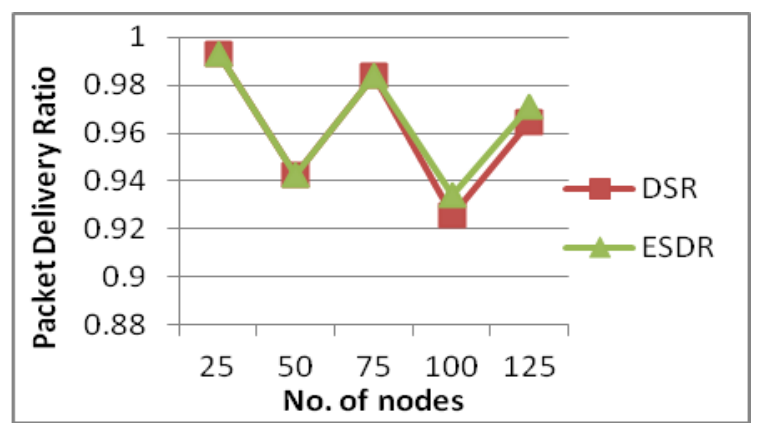

(a)Packet Delivery Ratio (512 bytes)

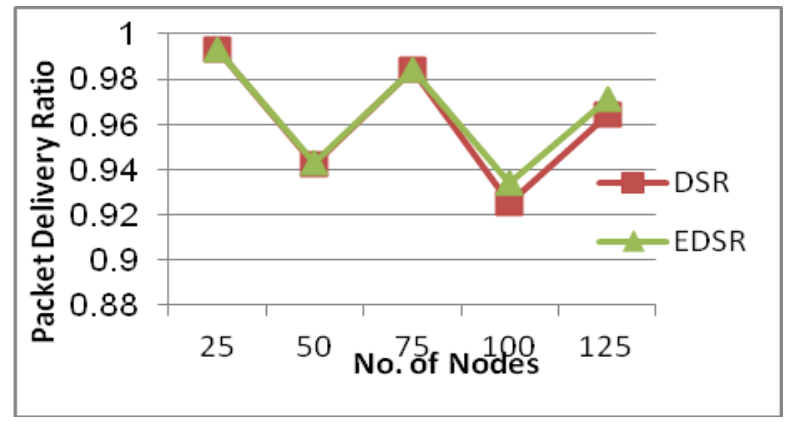

(b)Packet Delivery Ratio (1000 bytes) 


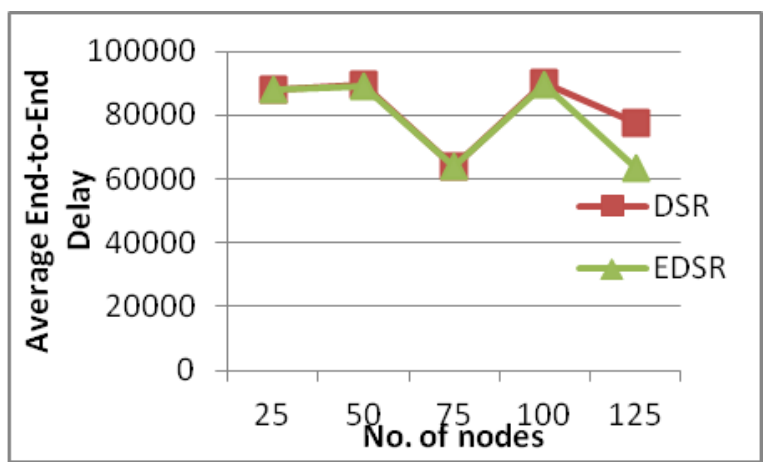

(c) Average End-to-end Delay (512 bytes)

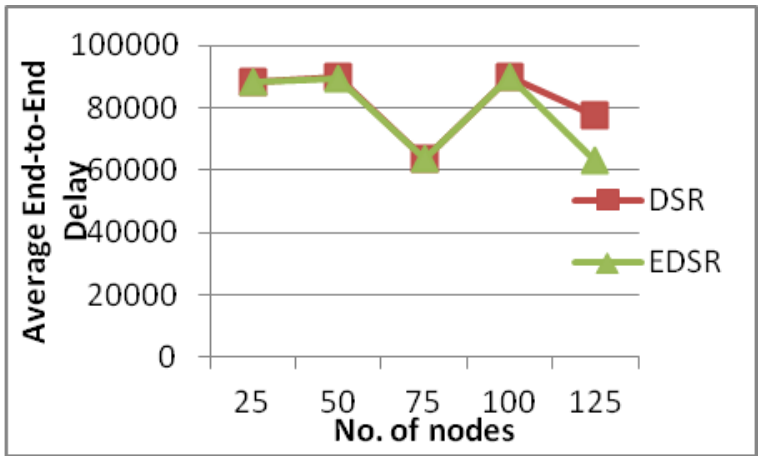

(d) Average End-to-End Delay 1000 bytes)

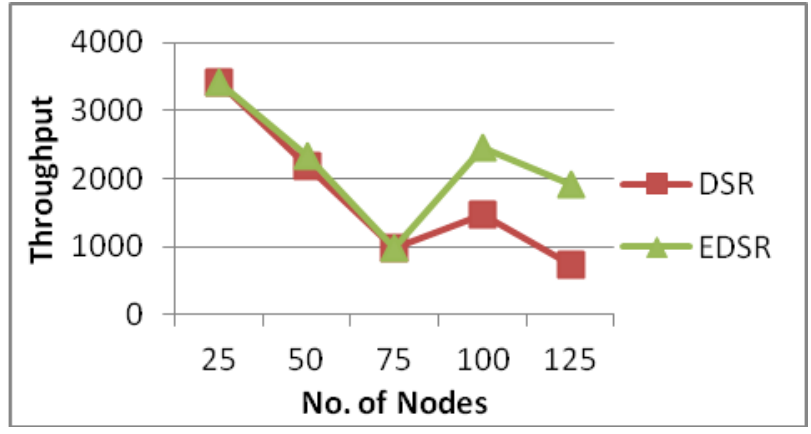

(e) Throughput (512 bytes)

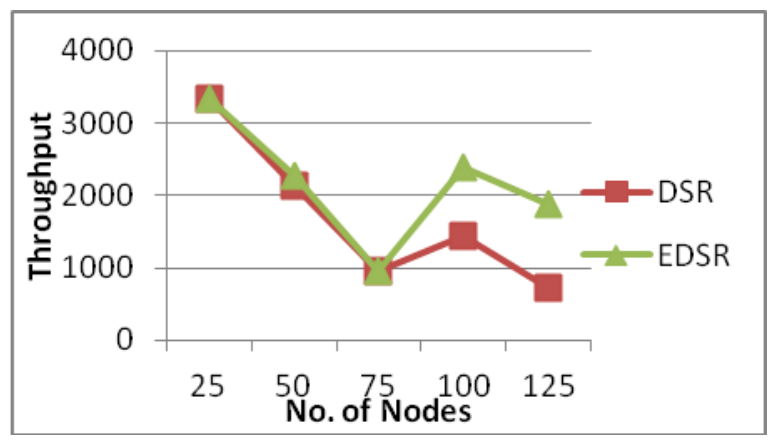

(f) Throughput (1000 bytes) 


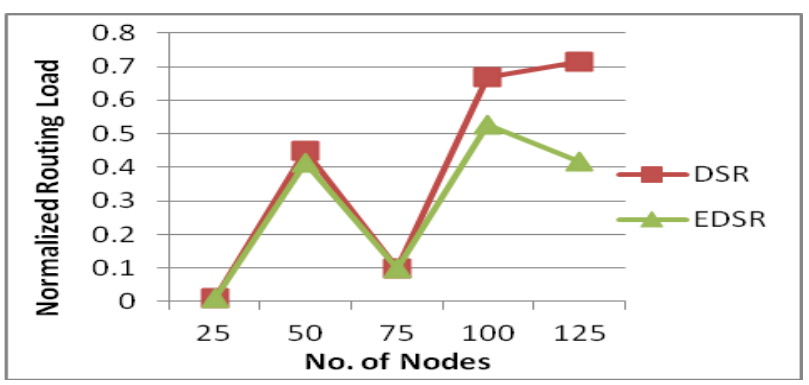

(g) Normalized Routing Load (512 bytes)

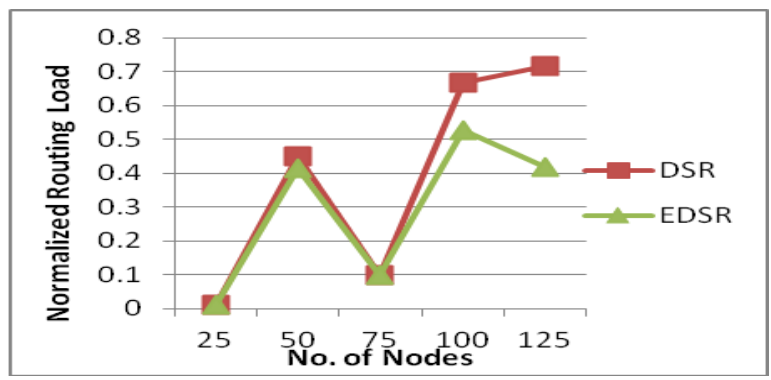

(h) Normalized Routing Load (1000 bytes)

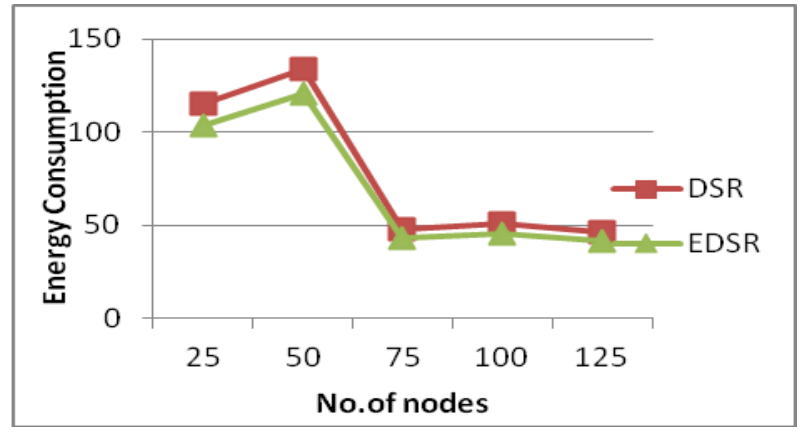

(i) Energy Consumption (512 bytes)

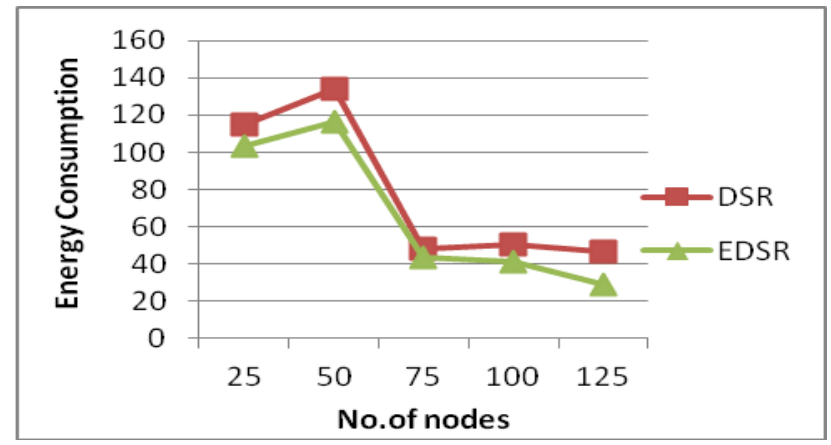

(j) Energy Consumption (1000 bytes)

Figure 4. Performance Analysis under TCP and FTP Traffic Condition by varying Number of Nodes and Packet Size (a) Variation of Packet Delivery

Ratio (512 bytes) (b) Variation of Packet Delivery Ratio (1000 bytes) (c) Variation of Average End-to-End Delay (512 bytes) (d) Variation of Average End-to-End Delay (1000 bytes) (e) Variation of Throughput (512 bytes) $(f)$ Variation of Throughput (1000 bytes) (g) Variation of Normalized Routing Load (512 bytes) (h) Variation of Normalized Routing Load (1000 bytes) (i) Variation of Energy Consumption (512 bytes) (j) Variation of Energy Consumption (1000 bytes) 


\subsubsection{Performance Analysis by Varying Number of Nodes}

Figure 4 shows the performance analysis of DSR and EDSR routing protocols under TCP and FTP traffic condition by varying number of nodes with different packet size. In Figure 4 (a) the variation of Packet Delivery Ratio is shown with packet size 512 bytes. The Packet Delivery Ratio in EDSR is more than the DSR routing protocol. In Figure4 (b) the variation of Packet Delivery Ratio is shown with packet size 1000 bytes. Again the Packet Delivery Ratio in EDSR is better than in DSR. In Figure 4 (c) the variation of Average End-to-End Delay is shown with packet size 512 bytes. When the numbers of nodes are 125 the Average End-to-End Delay in EDSR is very less than in DSR routing protocol. In Figure 4 (d) the variation of Average End-to-End Delay is shown with packet size 1000 bytes. Again the Average End-to-End Delay in EDSR is less than in DSR routing protocol. Figure 4 (e) shows the variation of throughput with 512 bytes packet size. The throughput in EDSR is more than in DSR routing protocol at higher number of nodes. Figure 4 (f) shows the variation of throughput with 1000 bytes packet size. The variation of throughput with 1000 bytes packet size is similar to 512 bytes packet size. Figure 4 (g) shows the variation of Normalized Routing Load with 512 bytes packet size. Normalized Routing Load is less in EDSR than in DSR routing protocol. Figure $4(\mathrm{~h})$ shows the variation of Normalized Routing Load with 1000 bytes packet size and the variation of Normalized Routing Load with respect to number of nodes with 1000 bytes packet size is similar to 512 bytes packet size. Figure 4 (i) shows the variation of Energy Consumption with 512 bytes packet size. Energy Consumption is less in EDSR than in DSR routing protocol. Figure 4 (j) shows the variation of Energy Consumption with 1000 bytes packet size. Energy Consumption is less in EDSR than in DSR routing protocol and decreases as number of nodes increases in EDSR routing protocol.

\subsection{Performance Analysis of DSR and EDSR by Varying Number of Nodes under UDP and CBR Traffic Condition with 512 Bytes and 1000 Bytes Packet Size}

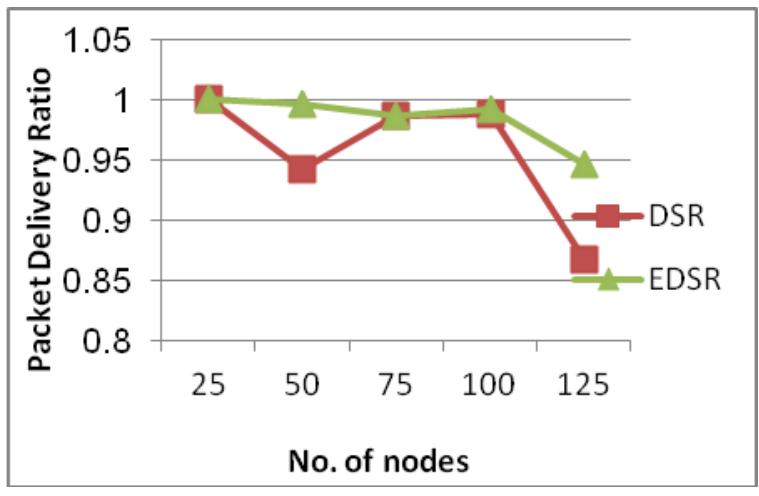

(a) Packet Delivery Ratio (512 bytes)

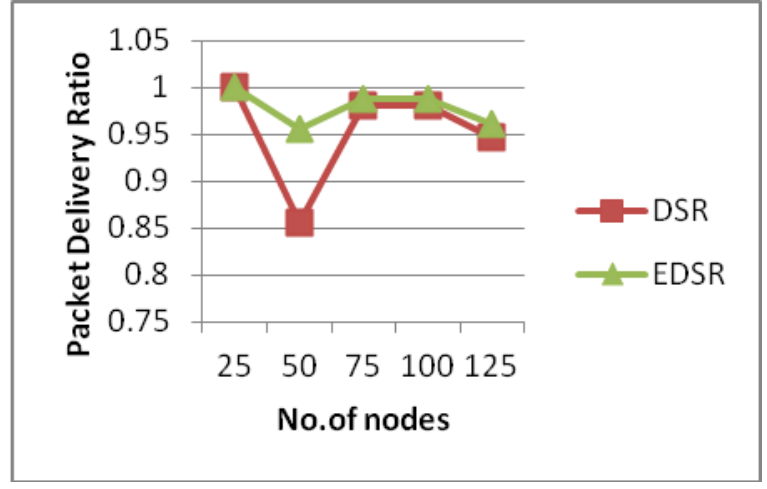

(b) Packet Delivery Ratio (1000 bytes) 
International Journal of Future Generation Communication and Networking Online Vol. 9, No. 4, (2016)

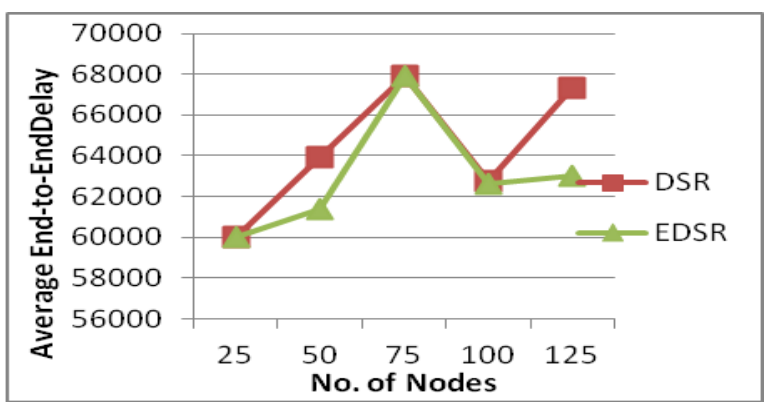

(c) Average End-to-end Delay (512 bytes)

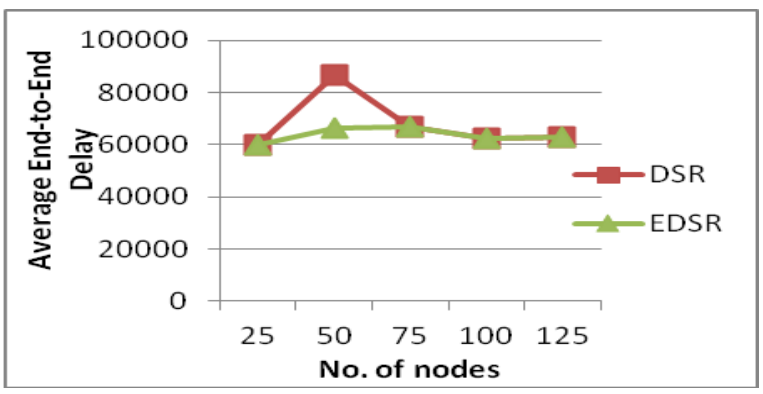

(d) Average End-to-End Delay 1000 bytes)

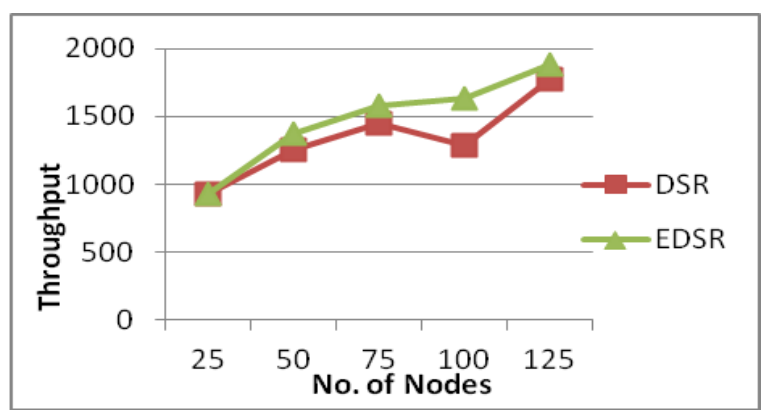

(e) Throughput (512 bytes)

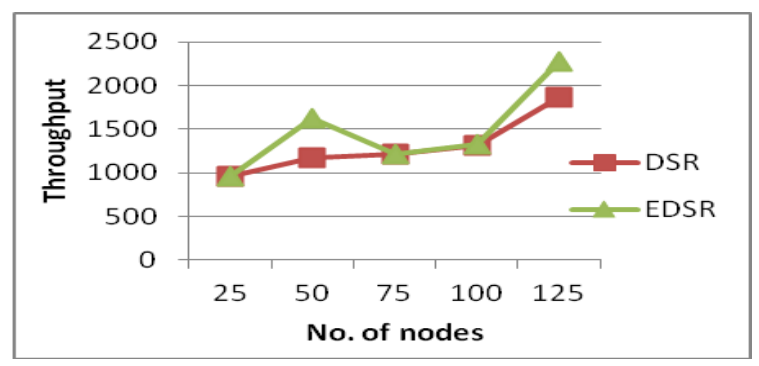

(f) Throughput (1000 bytes)

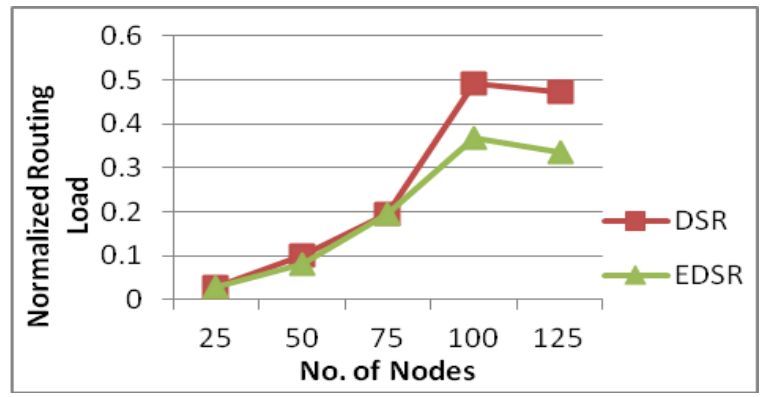

(g) Normalized Routing Load (512 bytes) 


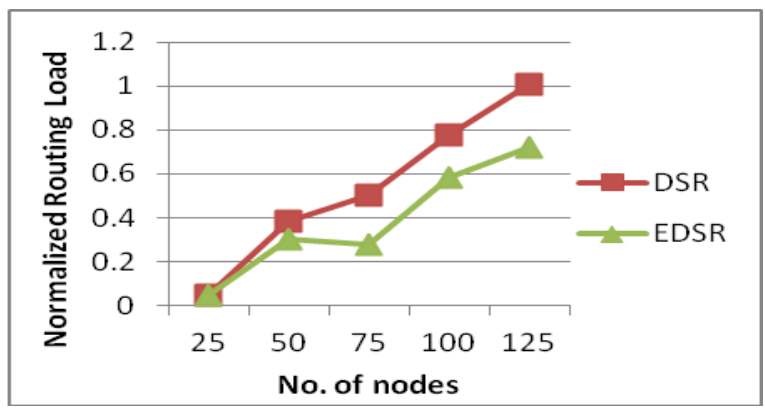

(h) Normalized Routing Load (1000 bytes)

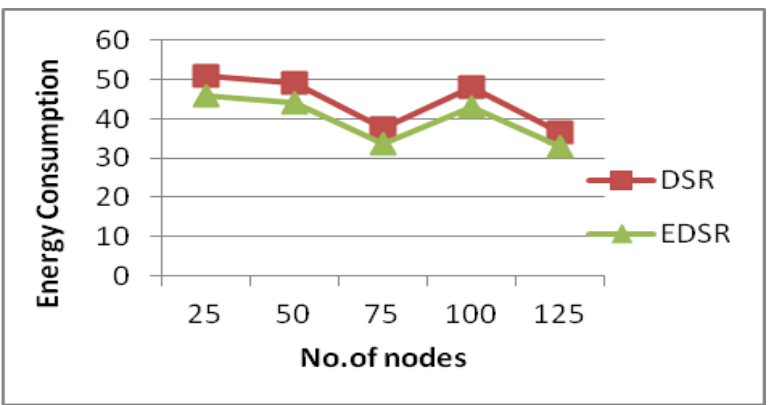

(i) Energy Consumption (512 bytes)

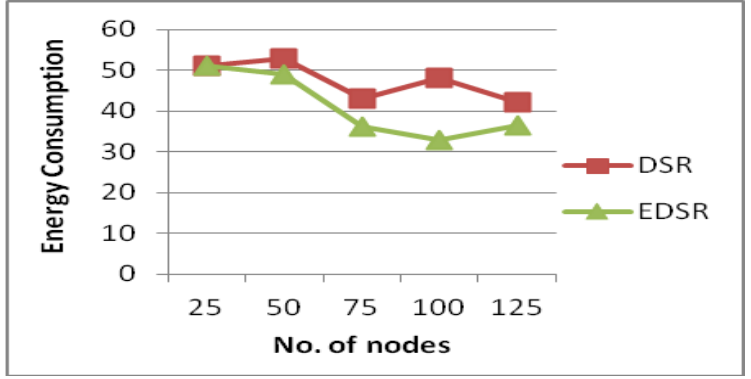

(j) Energy Consumption (1000 bytes)

Figure 5. Performance Analysis under UDP and CBR Traffic Condition by varying Number of Nodes and Different Packet Sizes (a) Variation of Packet Delivery Ratio (512 bytes) (b) Variation of Packet Delivery Ratio (1000 bytes)

(c) Variation of Average End-to-End Delay (512 bytes) (d) Variation of Average End-to-End Delay (1000 bytes) (e) Variation of Throughput (512 bytes) (f) Variation of Throughput (1000 bytes) (g) Variation of Normalized Routing Load (512 bytes) (h) Variation of Normalized Routing Load (1000 bytes) (i) Variation of Energy Consumption (512 bytes) (j) Variation of Energy Consumption (1000 bytes)

\subsubsection{Performance Analysis by Varying Number of Nodes}

Figure 5 shows the performance analysis of DSR and EDSR routing protocols under UDP and CBR traffic condition by varying number of nodes with different packet size. In Figure 5 (a) the variation of Packet Delivery Ratio is shown with packet size 512 bytes. The Packet Delivery Ratio in EDSR is much better than in DSR routing protocol. In Figure 5 (b) the variation of Packet Delivery Ratio is shown with packet size 1000 bytes. Again the Packet Delivery Ratio in EDSR is better than in DSR. In Figure5 (c) the variation of Average End-to-End Delay is shown with packet size 512 bytes. The Average End-to-End Delay in EDSR is very less than in DSR routing protocol and decreases as the number of nodes increases in EDSR routing protocol. In Figure5 (d) the variation of Average End-to-End Delay is shown with packet size 1000 bytes. Again the Average 
End-to-End Delay in EDSR is less than in DSR routing protocol. Figure5 (e) shows the variation of throughput with 512 bytes packet size. The throughput in EDSR is more than in DSR routing protocol and increases with the increase in number of nodes. Figure5 (f) shows the variation of throughput with 1000 bytes packet size. The variation of throughput with 1000 bytes packet size is similar to 512 bytes packet size. Figure 5 (g) shows the variation of Normalized Routing Load with 512 bytes packet size. Normalized Routing Load is less in EDSR than in DSR routing protocol and decreases with the increase in number of nodes in EDSR routing protocol. Figure 5 (h) shows the variation of Normalized Routing Load with 1000 bytes packet size. Normalized Routing Load in EDSR is less than in DSR routing protocol. Figure5 (i) shows the variation of Energy Consumption with 512 bytes packet size. Energy Consumption is less in EDSR than in DSR routing protocol. Figure5 (j) shows the variation of Energy Consumption with 1000 bytes packet size. Energy Consumption is less in EDSR than in DSR routing protocol.

5.4. Performance Analysis of DSR and EDSR by Varying Number of Nodes Under TCP and CBR Traffic Condition with Two Ray Ground and Shadowing Propagation Models

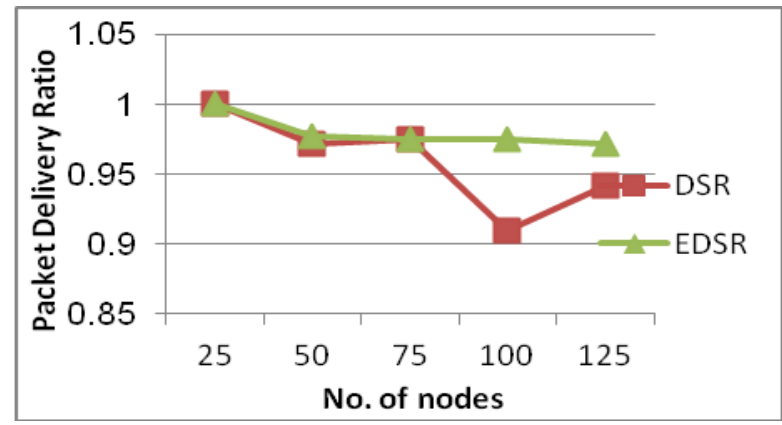

(a) Packet Delivery Ratio (Two ray ground)

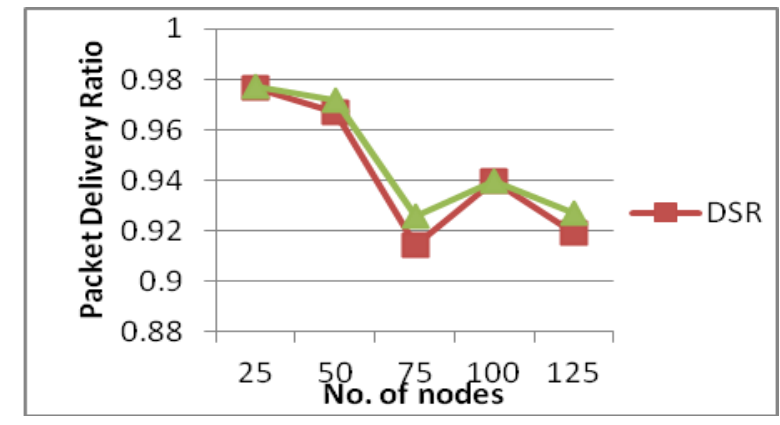

(b) Packet Delivery Ratio (shadowing)

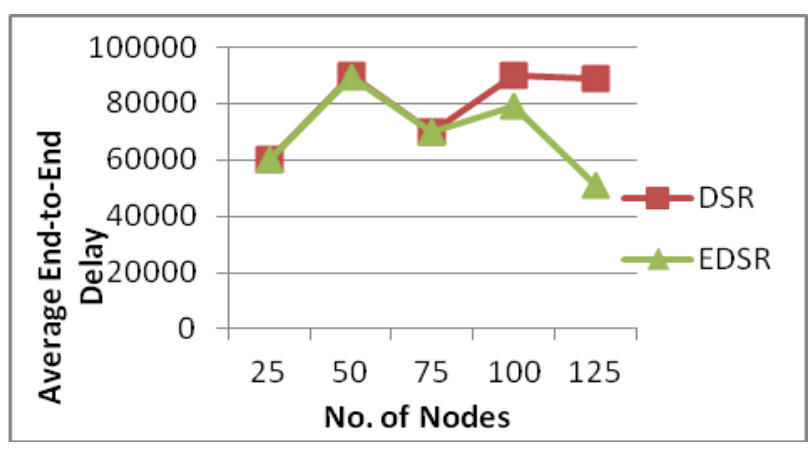

(c) Average End-to-end Delay (Two ray ground) 


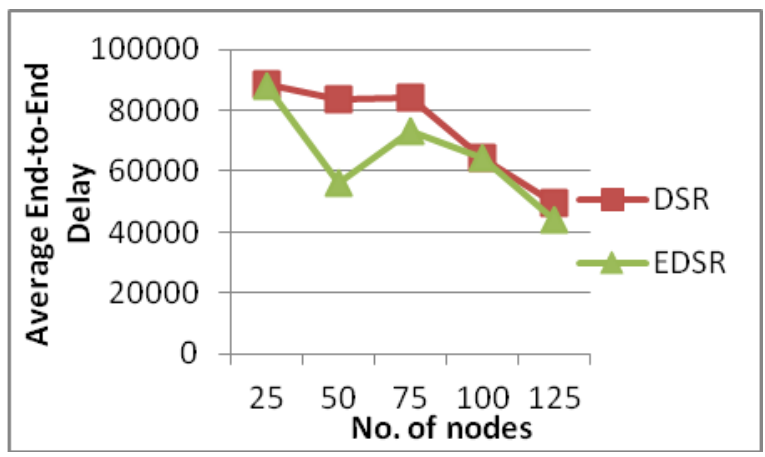

(d) Average End-to-End Delay (Shadowing)

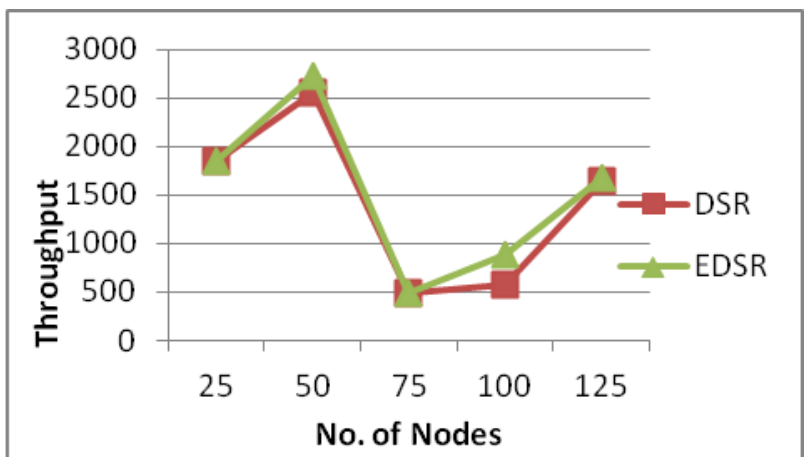

(e) Throughput (Two ray ground)

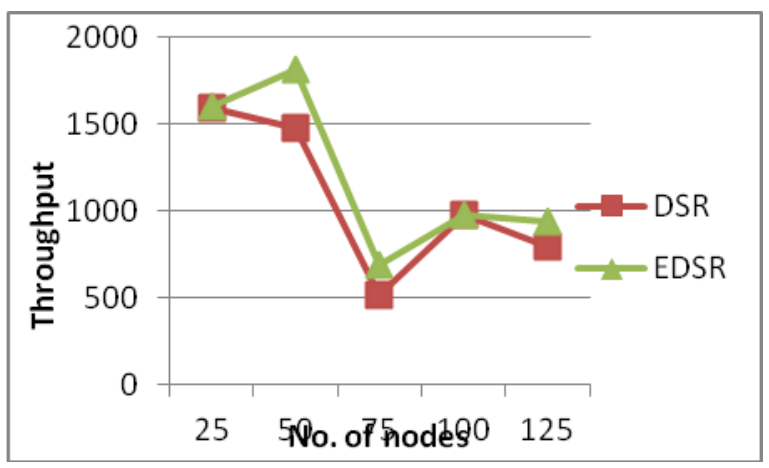

(f) Throughput (Shadowing)

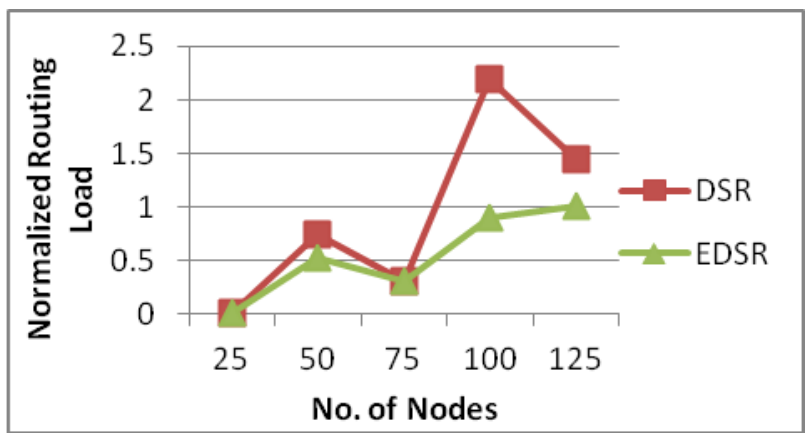

(g) Normalized Routing Load (Two ray ground) 


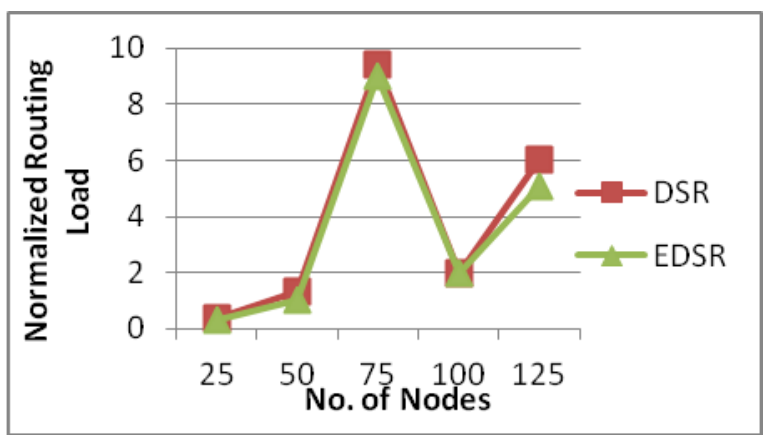

(h) Normalized Routing Load (Shadowing)

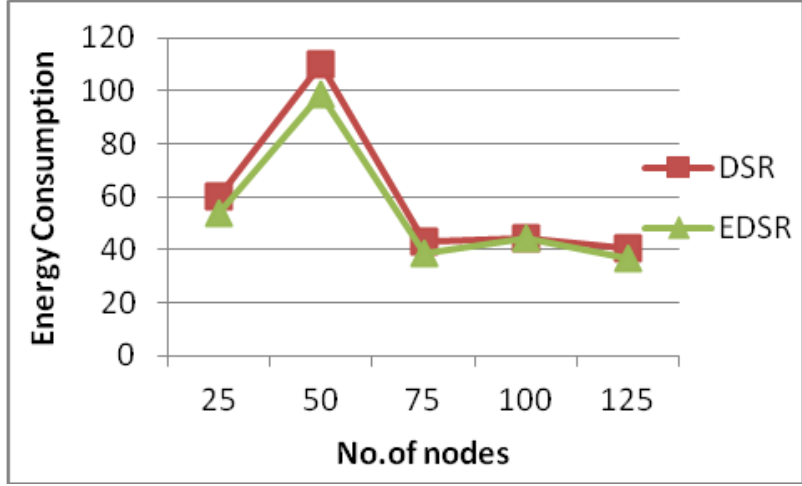

(i) Energy Consumption (Two ray ground)

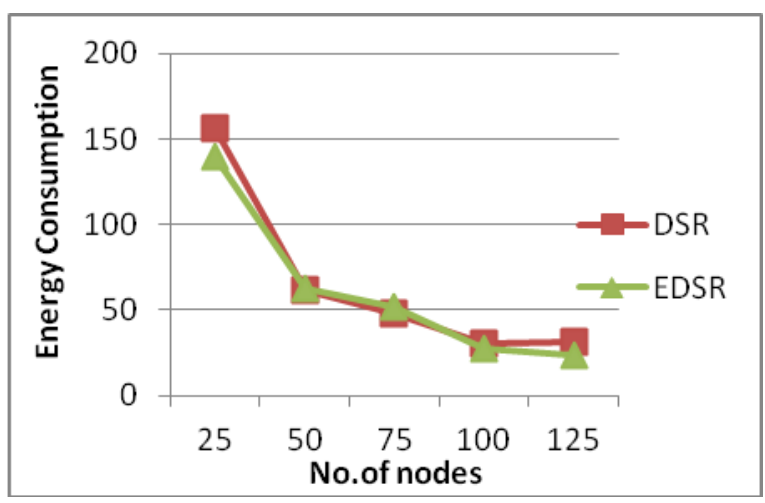

(j) Energy Consumption (Shadowing)

Figure 6. Performance Analysis under TCP and CBR Traffic Condition by varying Number of Nodes and Different Propagation Models (a) Variation of Packet Delivery Ratio (Two ray ground Propagation Model) (b) Variation of

Packet Delivery Ratio (Shadowing Propagation Model) (c) Variation of

Average End-to-End Delay (Two ray ground Propagation Model) (d)

Variation of Average End-to-End Delay (Shadowing Propagation Model) (e) Variation of Throughput (Two ray ground Propagation Model) (f) Variation of Throughput (Shadowing Propagation Model) (g) Variation of Normalized

Routing Load (Two ray ground Propagation Model) (h) Variation of Normalized Routing Load (Shadowing Propagation Model) (i) Variation of Energy Consumption (Two ray ground Propagation Model) (j) Variation of Energy Consumption (Shadowing Propagation Model) 


\subsubsection{Performance Analysis under Different Propagation Models}

Figure 6 shows the performance analysis of DSR and EDSR routing protocols under TCP and CBR traffic condition by varying number of nodes with different propagation models. In Figure 6 (a) the variation of Packet Delivery Ratio is shown with Two Ray Ground propagation model. The Packet Delivery Ratio in EDSR is much better than in DSR routing protocol. In Figure6 (b) the variation of Packet Delivery Ratio is shown with Shadowing propagation model. Again the Packet Delivery Ratio in EDSR is better than in DSR. In Figure6 (c) the variation of Average End-to-End Delay is shown with Two Ray Ground propagation model. The Average End-to-End Delay in EDSR is very less than in DSR routing protocol and decreases as the number of nodes increases in EDSR routing protocol. In Figure6 (d) the variation of Average End-to-End Delay is shown with Shadowing propagation model. Again the Average End-to-End Delay in EDSR is less than in DSR routing protocol and decreases as the number of nodes increases in EDSR routing protocol. Figure6 (e) shows the variation of throughput with Two Ray Ground propagation model. The throughput in EDSR is more than in DSR routing protocol and increases with the increase in number of nodes. Figure6 (f) shows the variation of throughput with Shadowing propagation model. The throughput in EDSR routing protocol is better than in DSR routing protocol. Figure6 $(\mathrm{g})$ shows the variation of Normalized Routing Load with Two Ray Ground propagation model. Normalized Routing Load is less in EDSR than in DSR routing protocol. Figure6 (h) shows the variation of Normalized Routing Load with Shadowing propagation model .Normalized Routing Load in EDSR is less with respect to DSR routing protocol. Figure6 (i) shows the variation of Energy Consumption with Two Ray Ground propagation model. Energy Consumption is less in EDSR than in DSR routing protocol. Figure6 (j) shows the variation of Energy Consumption with Shadowing propagation model. Energy Consumption is less in EDSR than in DSR routing protocol and decreases as number of nodes increases.

5.5. Performance Analysis of DSR and EDSR by varying number of nodes under TCP and FTP traffic condition with two ray ground and Shadowing propagation models.

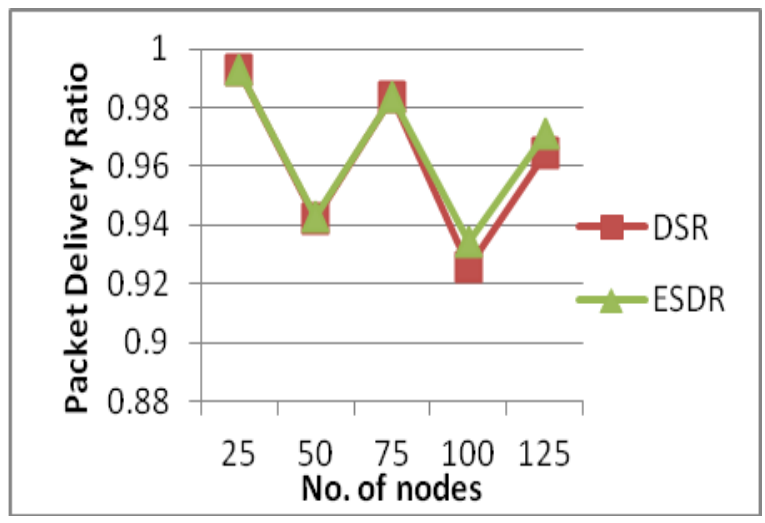

(a) Packet Delivery Ratio (Two ray ground) 
International Journal of Future Generation Communication and Networking Online Vol. 9, No. 4, (2016)

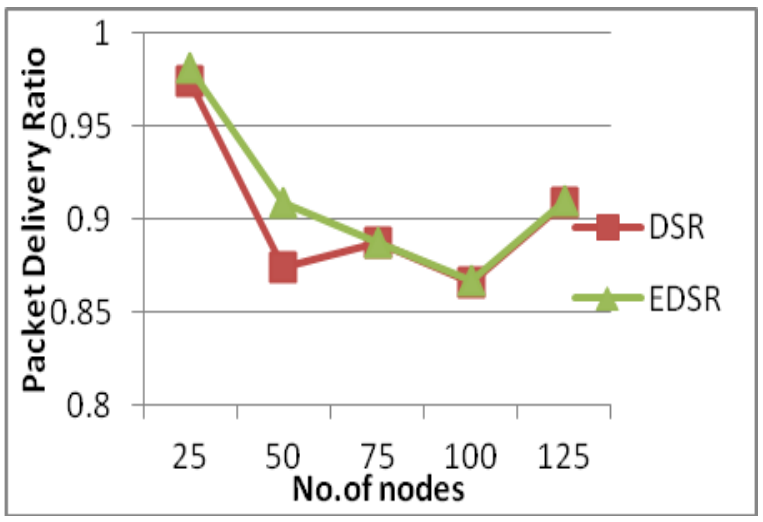

(b) Packet Delivery Ratio (Shadowing)

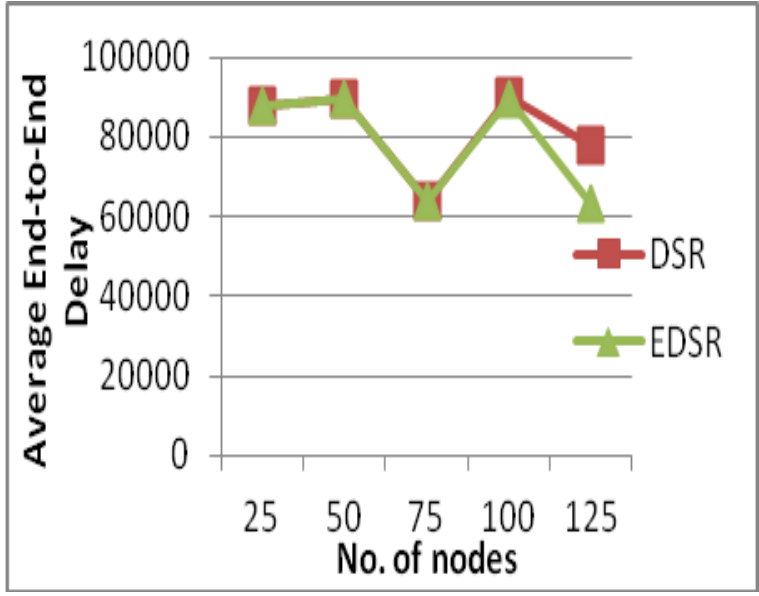

(c) Average End-to-end Delay (Two ray ground)

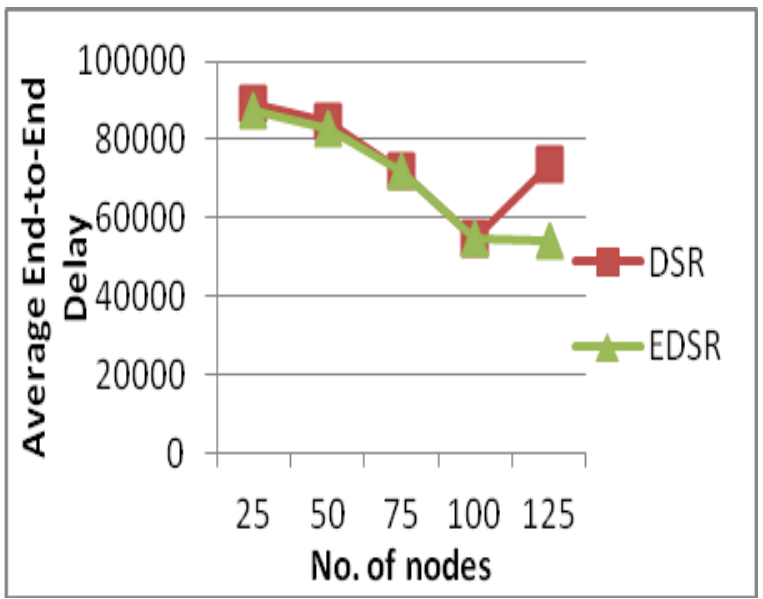

(d) Average End-to-End Delay (Shadowing) 


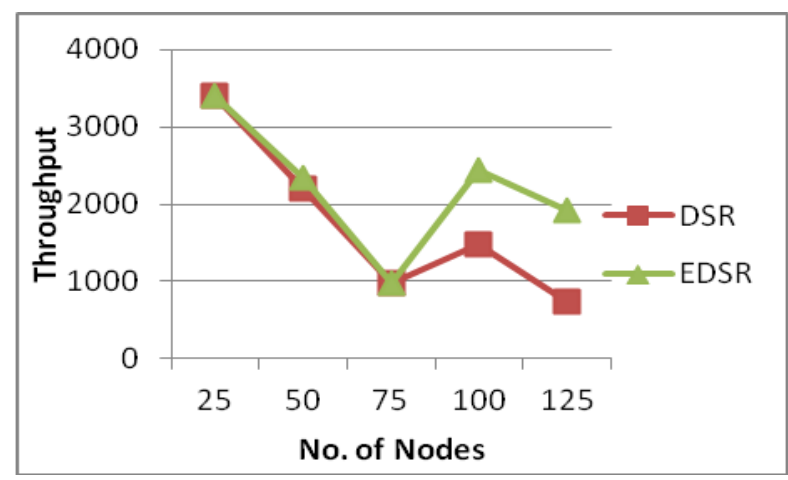

(e) Throughput (Two ray ground)

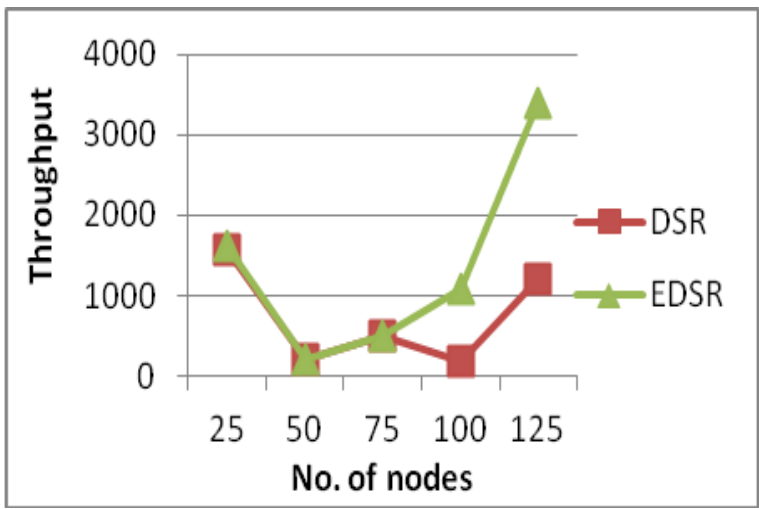

(f) Throughput (Shadowing)

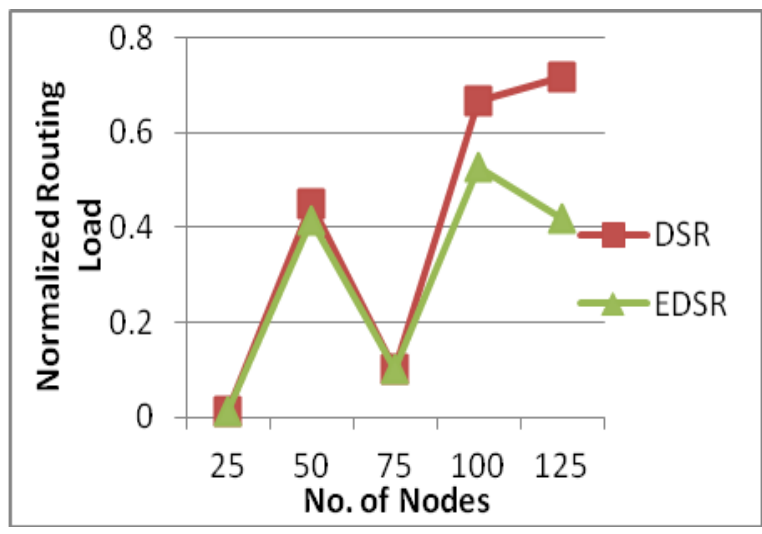

(g) Normalized Routing Load (Two ray ground)

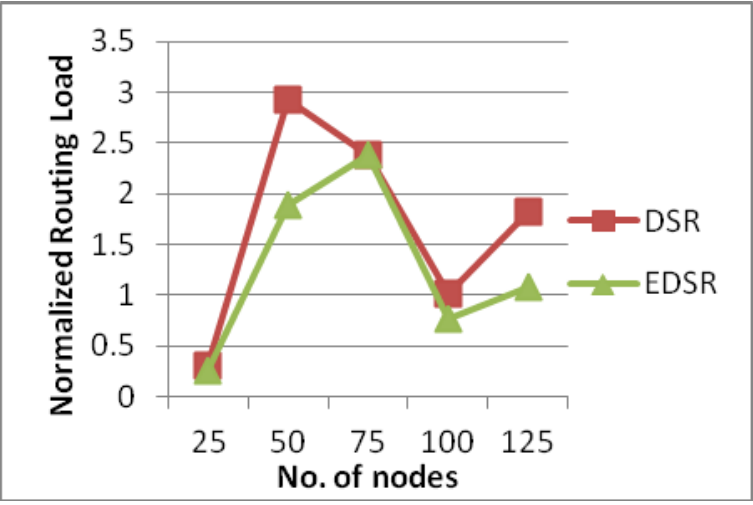

(h) Normalized Routing Load (Shadowing) 


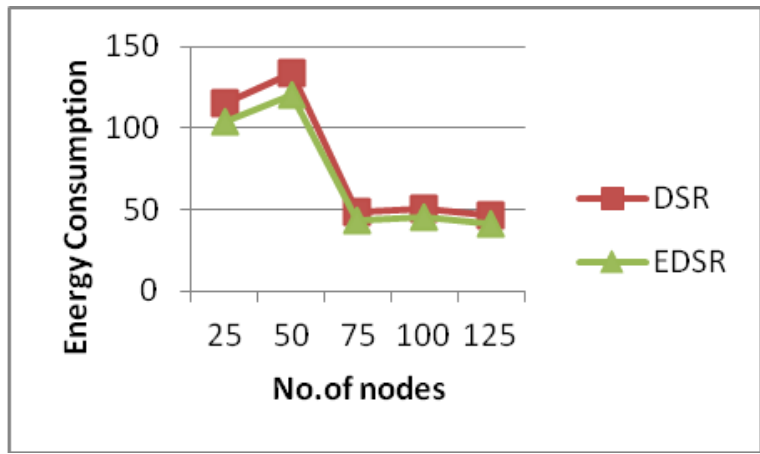

(i)

Energy Consumption (Two ray ground)

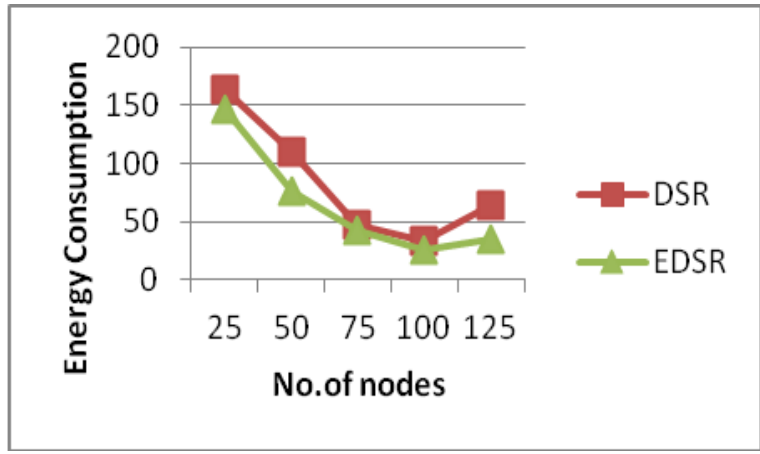

(j) Energy Consumption (Shadowing)

Figure 7. Performance Analysis under TCP and FTP Traffic Condition by varying Number of Nodes and Different Propagation Models (a) Variation of Packet Delivery Ratio (Two ray ground Propagation Model) (b) Variation of Packet Delivery Ratio (Shadowing Propagation Model) (c) Variation of Average End-to-End Delay (Two ray ground Propagation Model) (d) Variation of Average End-to-End Delay (Shadowing Propagation Model) (e) Variation of Throughput (Two ray ground Propagation Model) (f) Variation of Throughput (Shadowing Propagation Model) (g) Variation of Normalized Routing Load (Two ray ground Propagation Model) (h) Variation of Normalized Routing Load (Shadowing Propagation Model) (i) Variation of Energy Consumption (Two ray ground Propagation Model) (j) Variation of Energy Consumption (Shadowing Propagation Model)

\subsubsection{Performance Analysis under Different Propagation Models}

Figure7 shows the performance analysis of DSR and EDSR routing protocols under TCP and FTP traffic condition by varying number of nodes with different propagation models. In Figure 7 (a) the variation of Packet Delivery Ratio (PDR) is shown with Two Ray Ground propagation model. The Packet Delivery Ratio in EDSR is better than in DSR routing protocol. In Figure7 (b) the variation of Packet Delivery Ratio is shown with Shadowing propagation model. Again the Packet Delivery Ratio in EDSR is better than in DSR. In Figure7 (c) the variation of Average End-to-End Delay is shown with Two Ray Ground propagation model. The Average End-to-End Delay in EDSR is less than in DSR routing protocol. In Figure7 (d) the variation of Average End-to-End Delay is shown with Shadowing propagation model. Again the Average End-to-End Delay in EDSR is less than in DSR routing protocol. Figure7 (e) shows the variation of throughput with Two Ray Ground propagation model. The throughput in EDSR is more than in DSR routing protocol. Figure7 (f) shows the variation of throughput with Shadowing propagation model. The throughput in EDSR routing protocol is better than in DSR routing protocol. 
Figure7 (g) shows the variation of Normalized Routing Load with Two Ray Ground propagation model. Normalized Routing Load is less in EDSR than in DSR routing protocol. Figure7 (h) shows the variation of Normalized Routing Load with Shadowing propagation model .Normalized Routing Load in EDSR is less than in DSR routing protocol. Figure7 (i) shows the variation of Energy Consumption with Two Ray Ground propagation model. Energy Consumption is less in EDSR than in DSR routing protocol. Figure7 (j) shows the variation of Energy Consumption with Shadowing propagation model. Energy Consumption is less in EDSR than in DSR routing protocol and decreases as number of nodes increases.

5.6. Performance Analysis of DSR and EDSR by varying number of nodes under UDP and CBR traffic condition with two ray ground and Shadowing propagation models.

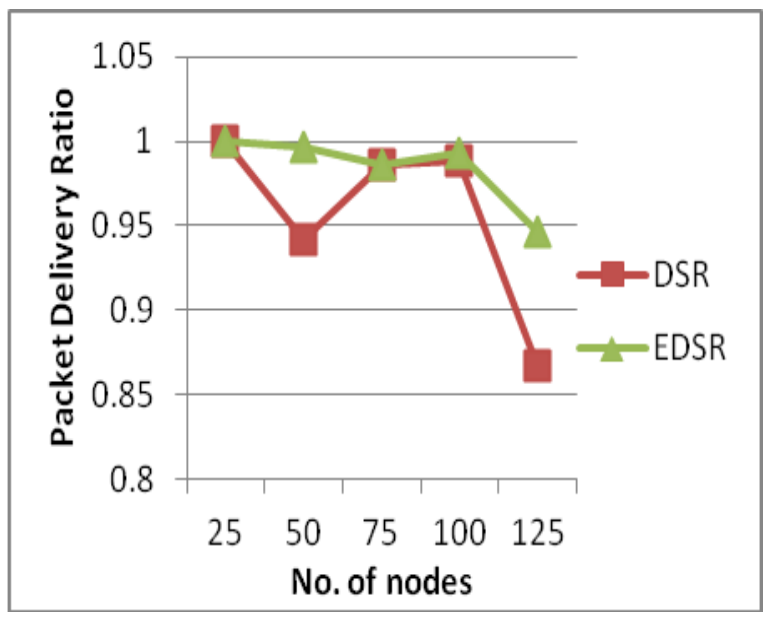

(a)Packet Delivery Ratio (Two ray ground)

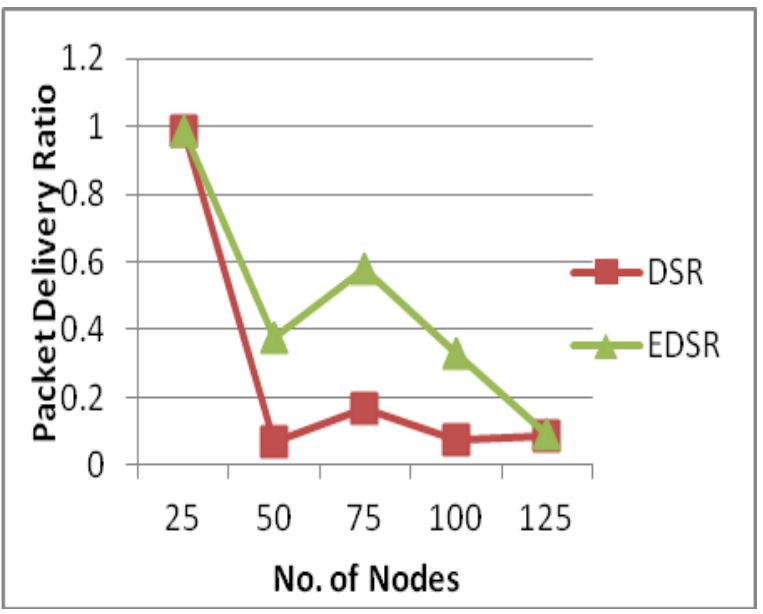

(c) Packet Delivery Ratio (shadowing) 
International Journal of Future Generation Communication and Networking Online Vol. 9, No. 4, (2016)

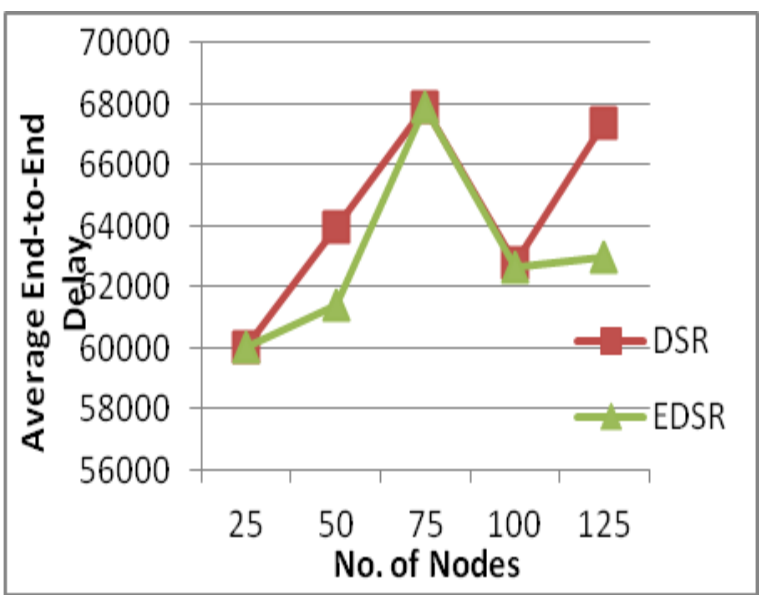

(c) Average End-to-end Delay (Two ray ground)

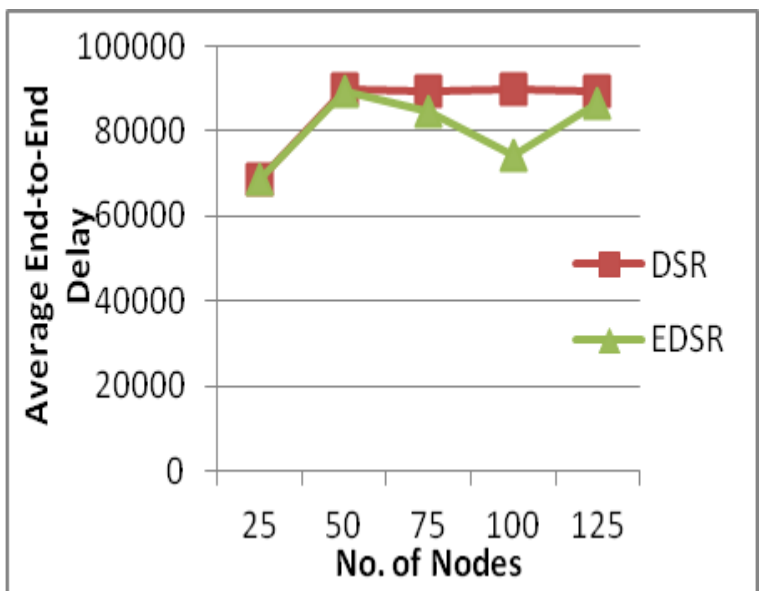

(d) Average End-to-End Delay (Shadowing)

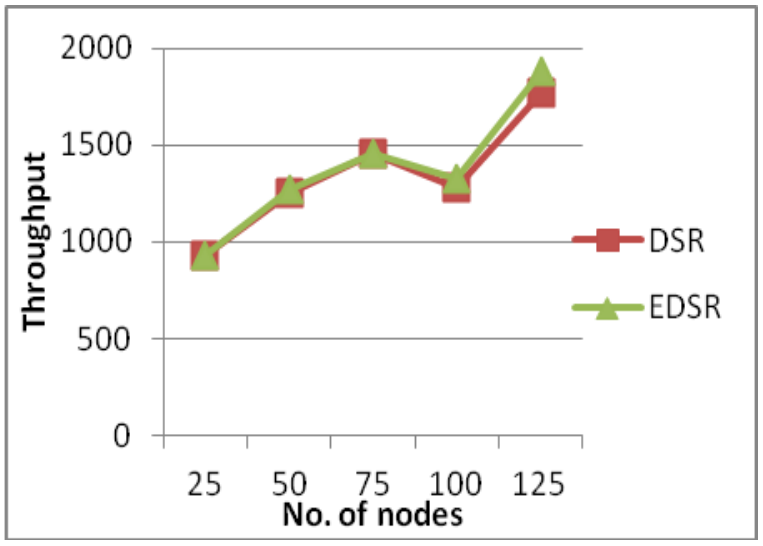

(e) Throughput (Two ray ground) 


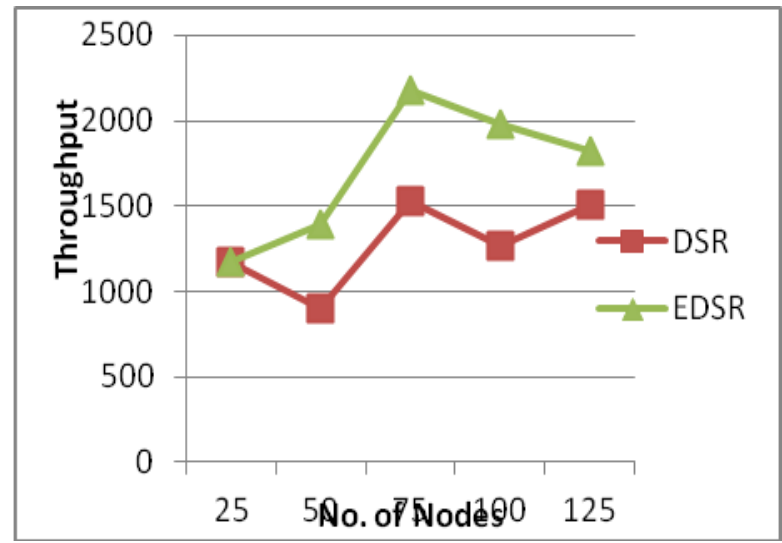

(f) Throughput (Shadowing)

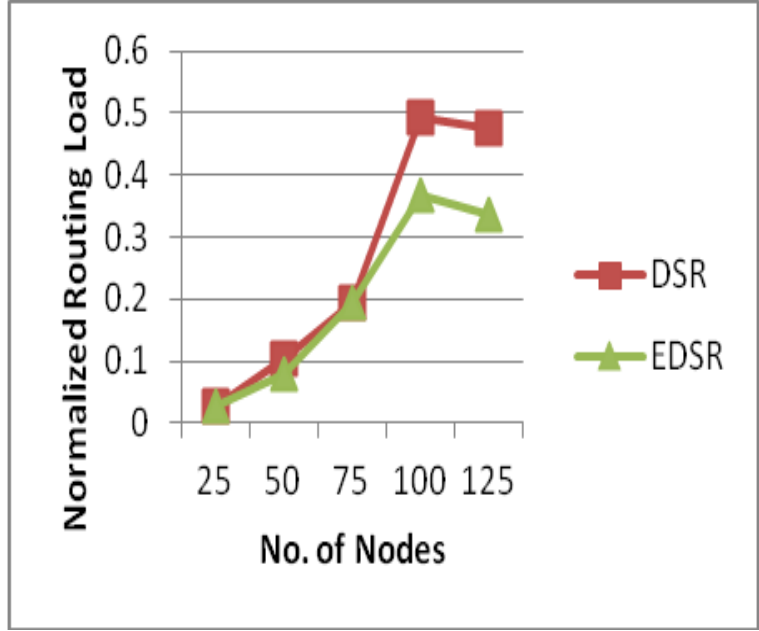

(g) Normalized Routing Load (Two ray ground)

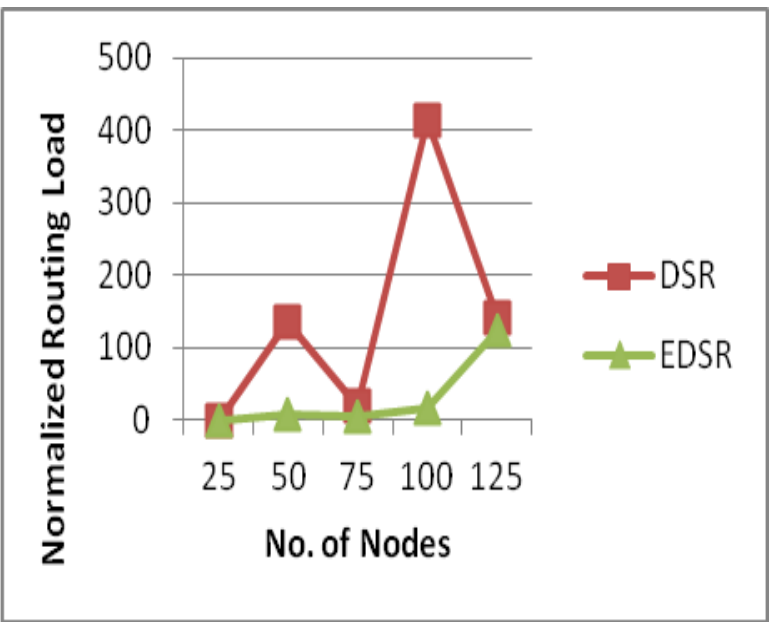

(h) Normalized Routing Load (Shadowing) 


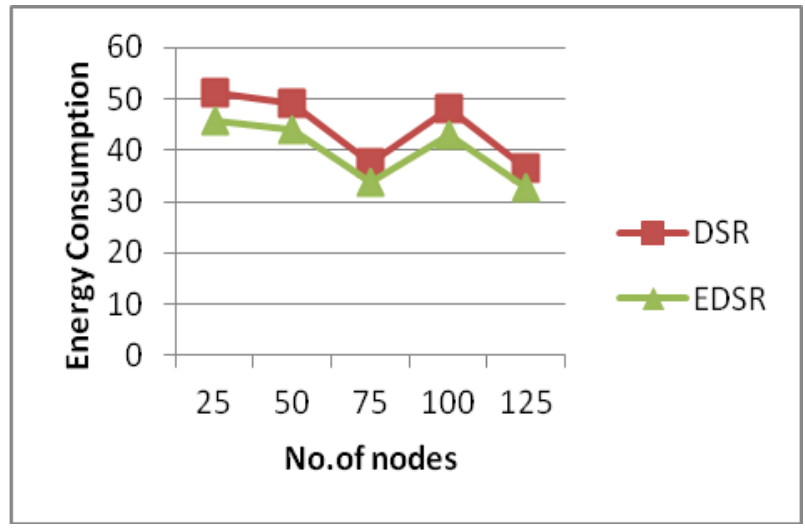

(i) Energy Consumption (Two ray ground)

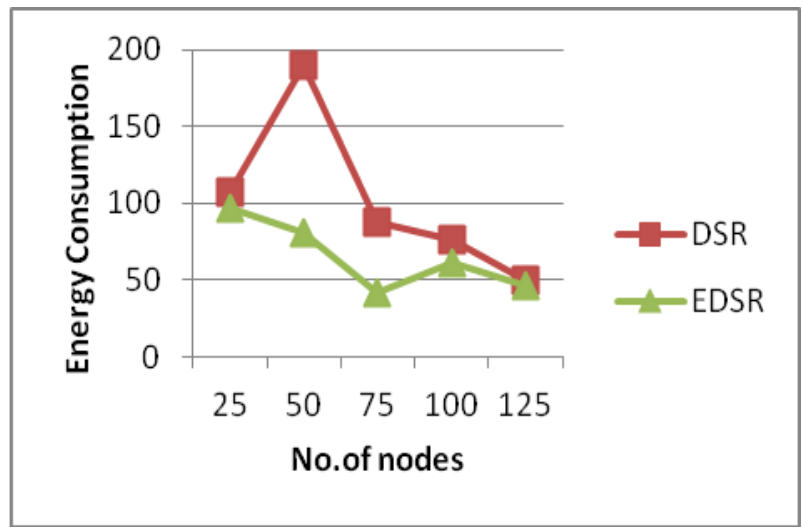

(j) Energy Consumption (Shadowing)

Figure 8. Performance Analysis under UDP and CBR Traffic condition by varying Number of Nodes and different propagation models (a) Variation of Packet Delivery Ratio (Two ray ground Propagation Model) (b) Variation of Packet Delivery Ratio (Shadowing Propagation Model) (c) Variation of Average End-to-End Delay (Two ray ground Propagation Model) (d)

Variation of Average End-to-End Delay (Shadowing Propagation Model) (e) Variation of Throughput (Two ray ground Propagation Model) (f) Variation of Throughput (Shadowing Propagation Model) (g) Variation of Normalized Routing Load (Two ray ground Propagation Model) (h) Variation of Normalized Routing Load (Shadowing Propagation Model) (i) Variation of Energy Consumption (Two ray ground Propagation Model) (j) Variation of Energy Consumption (Shadowing Propagation Model)

\subsubsection{Performance analysis under different propagation models}

Figure 8 shows the performance analysis of DSR and EDSR routing protocols under UDP and CBR traffic condition by varying number of nodes with different propagation models. In Figure 8 (a) the variation of Packet Delivery Ratio is shown with Two Ray Ground propagation model. The Packet Delivery Ratio in EDSR is much better than in DSR routing protocol. In Figure8 (b) the variation of Packet Delivery Ratio is shown with Shadowing propagation model. Again the Packet Delivery Ratio in EDSR is better than in DSR. In Figure8 (c) the variation of Average End-to-End Delay is shown with Two Ray Ground propagation model. The Average End-to-End Delay in EDSR is less than in DSR routing protocol. In Figure8 (d) the variation of Average End-to-End Delay is shown with Shadowing propagation model. Again the Average End-to-End Delay in EDSR is less than in DSR routing protocol. Figure8 (e) shows the variation of throughput with Two 
Ray Ground propagation model. The throughput in EDSR is more than in DSR routing protocol. Figure8 (f) shows the variation of throughput with Shadowing propagation model. The throughput in EDSR routing protocol is much better than in DSR routing protocol. Figure8 (g) shows the variation of Normalized Routing Load with Two Ray Ground propagation model. Normalized Routing Load is less in EDSR than in DSR routing protocol. Figure8 (h) shows the variation of Normalized Routing Load with Shadowing propagation model .Normalized Routing Load in EDSR is less than in DSR routing protocol. Figure8 (i) shows the variation of Energy Consumption with Two Ray Ground propagation model. Energy Consumption is less in EDSR than in DSR routing protocol. Figure8 (j) shows the variation of Energy Consumption with Shadowing propagation model. Energy Consumption is less in EDSR than in DSR routing protocol.

5.7. Performance Analysis of DSR and EDSR by varying number of nodes under TCP and CBR traffic condition with $1000 \mathrm{~m} * 1000 \mathrm{~m}$ network size and $1500 \mathrm{~m} * 1500 \mathrm{~m}$ network size.

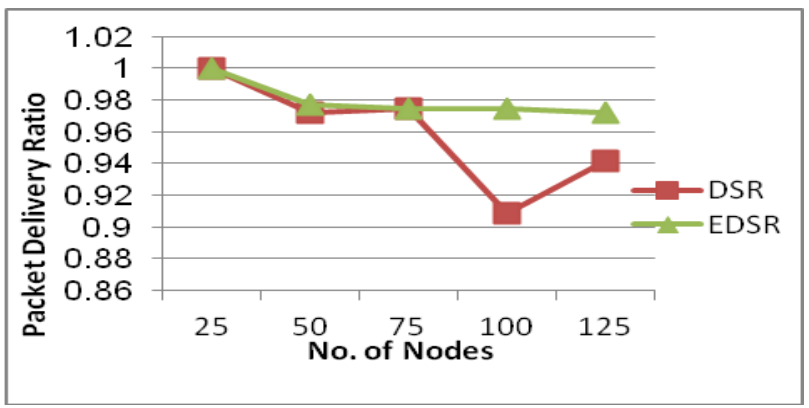

(a)Packet Delivery Ratio $\left(1000 m^{*} 1000 m\right)$

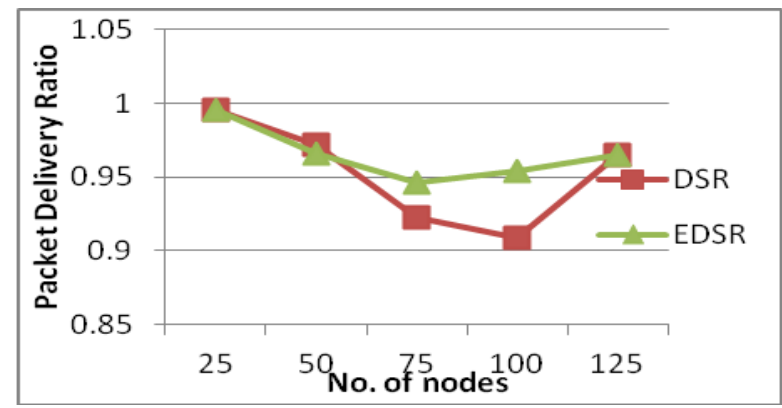

(b) Packet Delivery Ratio $\left(1500 m^{*} 1500 \mathrm{~m}\right)$

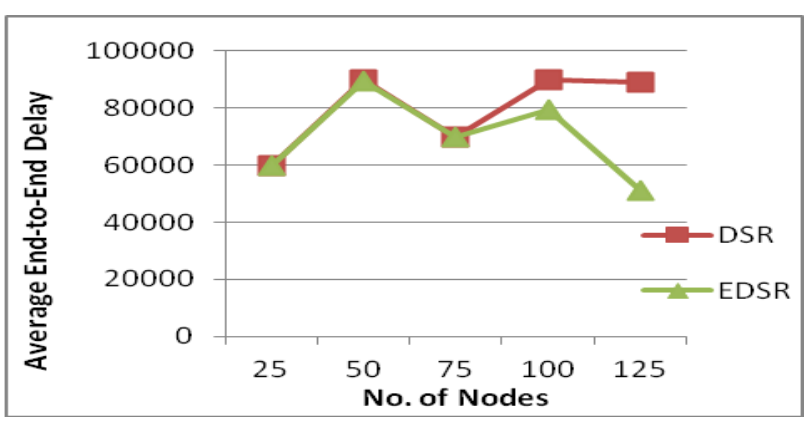

(c) Average End-to-end Delay $\left(1000 \mathrm{~m}^{*} 1000 \mathrm{~m}\right)$ 
International Journal of Future Generation Communication and Networking Online Vol. 9, No. 4, (2016)

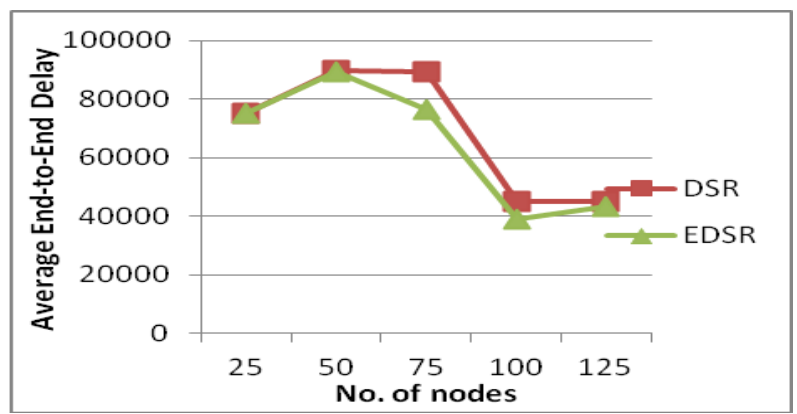

(d) Average End-to-End Delay (1500m*1500m)

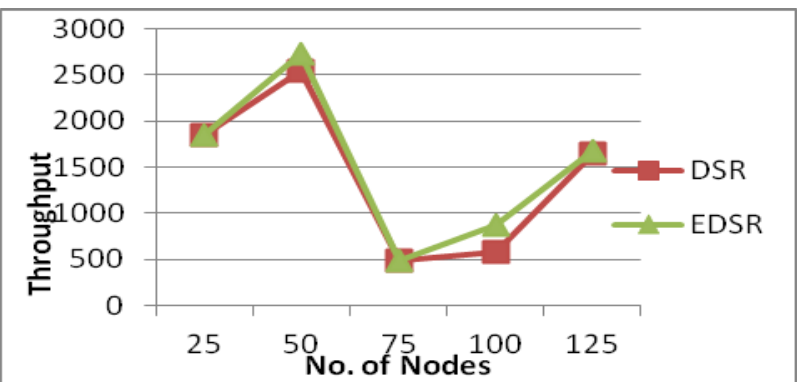

(e) Throughput $\left(1000 \mathrm{~m}^{*} 1000 \mathrm{~m}\right)$

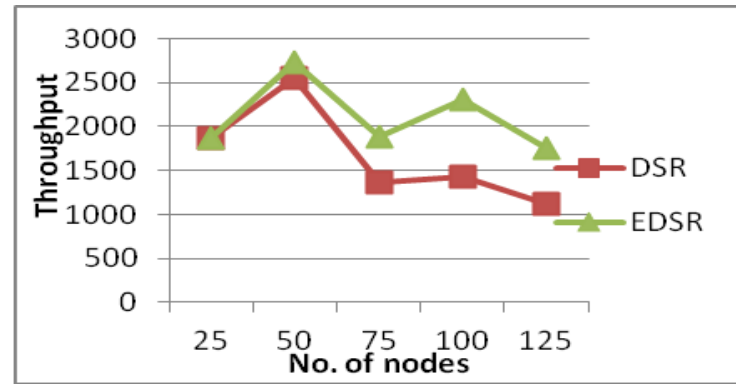

(f) Throughput (1500m*1500m)

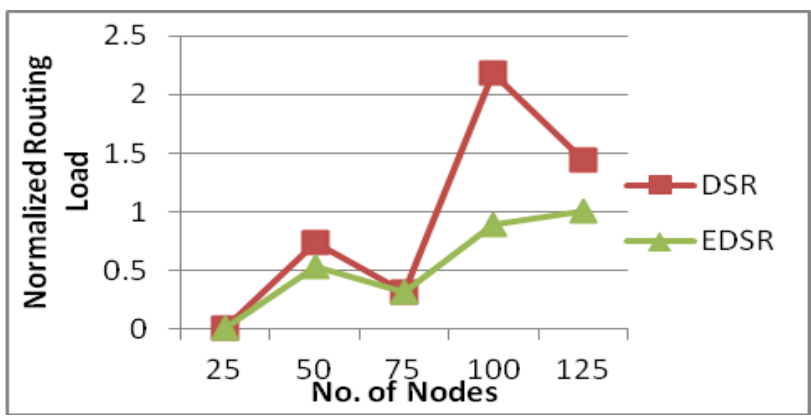

(g) Normalized Routing Load $\left(1000 m^{*} 1000 m\right)$ 


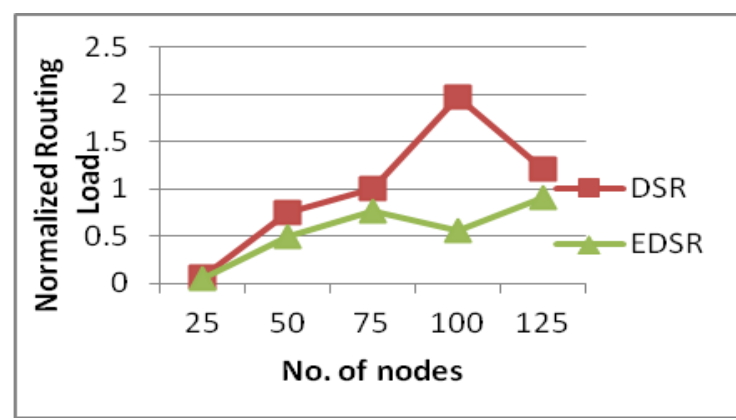

(h) Normalized Routing Load $\left(1500 m^{*} 1500 m\right)$

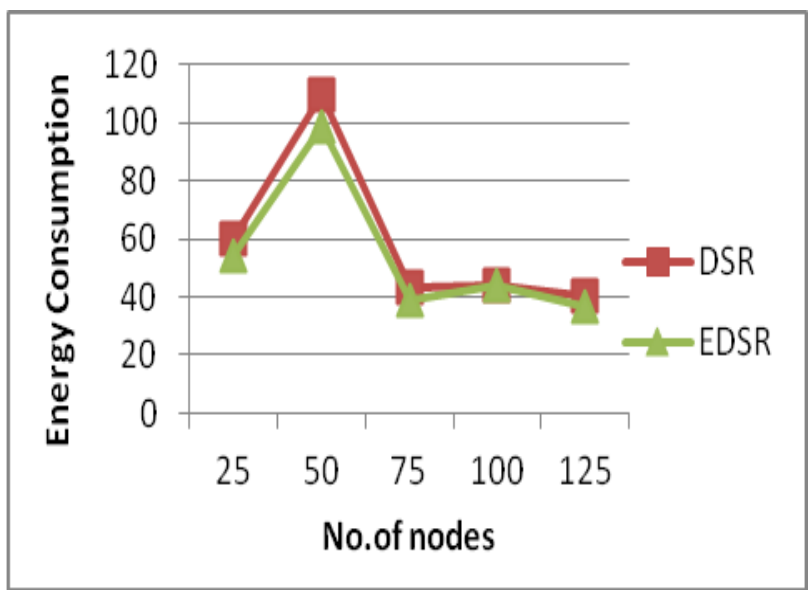

(i) Energy Consumption $\left(1000 \mathrm{~m}^{\star} 1000 \mathrm{~m}\right)$

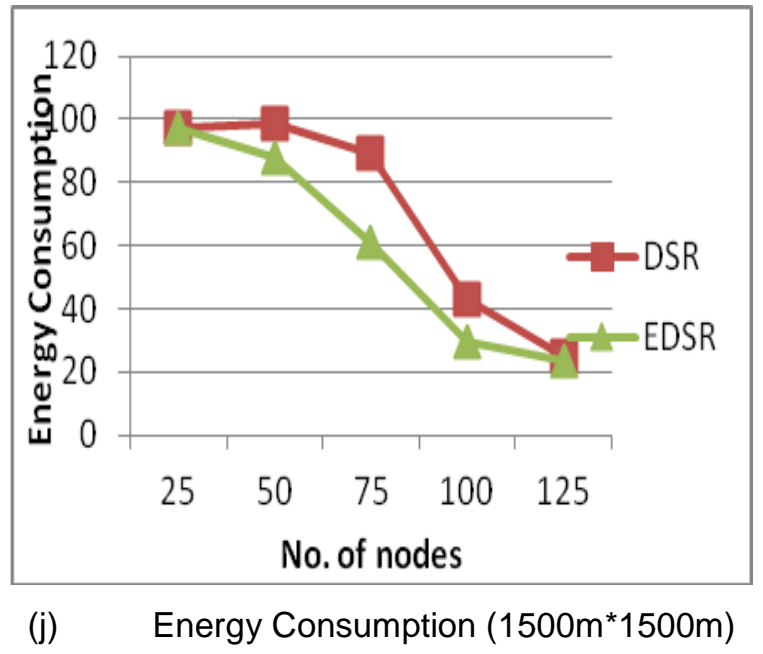

Figure 9. Performance Analysis under TCP and CBR Traffic condition by varying Number of Nodes and different network size i.e. $1000 \mathrm{~m}^{\star} 1000 \mathrm{~m}$ and $1500 \mathrm{~m}^{*} 1500 \mathrm{~m}$ (a) Variation of Packet Delivery Ratio $\left(1000 \mathrm{~m}^{\star} 1000 \mathrm{~m}\right)(\mathrm{b})$ Variation of Packet Delivery Ratio $\left(1500 \mathrm{~m}^{*} 1500 \mathrm{~m}\right)$ (c) Variation of Average End-to-End Delay $\left(1000 \mathrm{~m}^{\star} 1000 \mathrm{~m}\right)$ (d) Variation of Average End-to-End Delay $\left(1500 \mathrm{~m}^{*} 1500 \mathrm{~m}\right)(\mathrm{e})$ Variation of Throughput $\left(1000 \mathrm{~m}^{*} 1000 \mathrm{~m}\right)(\mathrm{f})$ Variation of Throughput $\left(1500 \mathrm{~m}^{*} 1500 \mathrm{~m}\right)(\mathrm{g})$ Variation of Normalized Routing Load $\left(1000 m^{\star} 1000 \mathrm{~m}\right)(\mathrm{h})$ Variation of Normalized Routing Load $\left(1500 \mathrm{~m}^{\star} 1500 \mathrm{~m}\right)(\mathrm{i})$ Variation of Energy Consumption $\left(1000 \mathrm{~m}^{*} 1000 \mathrm{~m}\right)(\mathrm{j})$ Variation of Energy Consumption $\left(1500 \mathrm{~m}^{\star} 1500 \mathrm{~m}\right)$ 


\subsubsection{Performance Analysis under Different Network Size}

Figure 9 shows the performance analysis of DSR and EDSR routing protocols under TCP and CBR traffic condition by varying number of nodes with different network size. In Figure 9 (a) the variation of Packet Delivery Ratio is shown with $1000 \mathrm{~m} * 1000 \mathrm{~m}$ network size. The Packet Delivery Ratio in EDSR is much better than in DSR routing protocol at higher number of nodes i.e. 100 and 125. In Figure9 (b) the variation of Packet Delivery Ratio is shown with $1500 \mathrm{~m}^{*} 1500 \mathrm{~m}$. Again the Packet Delivery Ratio in EDSR is better than in DSR. In Figure9 (c) the variation of Average End-to-End Delay is shown with 1000m*1000m network size. The Average End-to-End Delay in EDSR is less than in DSR routing protocol. In Figure9 (d) the variation of Average End-to-End Delay is shown with $1500 \mathrm{~m} * 1500 \mathrm{~m}$ network size. Again the Average End-to-End Delay in EDSR is less than in DSR routing protocol. Figure9 (e) shows the variation of throughput with $1000 \mathrm{~m}^{*} 1000 \mathrm{~m}$ network size. The throughput in EDSR is more than in DSR routing protocol. Figure9 (f) shows the variation of throughput with $1500 \mathrm{~m}^{*} 1500 \mathrm{~m}$ network size. The throughput in EDSR routing protocol is much better than in DSR routing protocol. Figure9 (g) shows the variation of Normalized Routing Load with $1000 \mathrm{~m}^{*} 1000 \mathrm{~m}$ network size. Normalized Routing Load is less in EDSR than in DSR routing protocol. Figure9 (h) shows the variation of Normalized Routing Load with $1000 \mathrm{~m} * 1000 \mathrm{~m}$ network size. Normalized Routing Load in EDSR is less than in DSR routing protocol. Figure9 (i) shows the variation of Energy Consumption with $1000 \mathrm{~m} * 1000 \mathrm{~m}$ network size. Energy Consumption is less in EDSR than in DSR routing protocol. Figure9 (j) shows the variation of Energy Consumption with $1500 \mathrm{~m} * 1500 \mathrm{~m}$ network size. Energy Consumption in EDSR is less than in DSR routing protocol.

5.8. Performance Analysis of DSR and EDSR by Varying Number of Nodes under TCP and FTP Traffic Condition with $1000 \mathrm{~m} * 1000 \mathrm{~m}$ Network Size and $1500 m * 1500 m$ Network Size

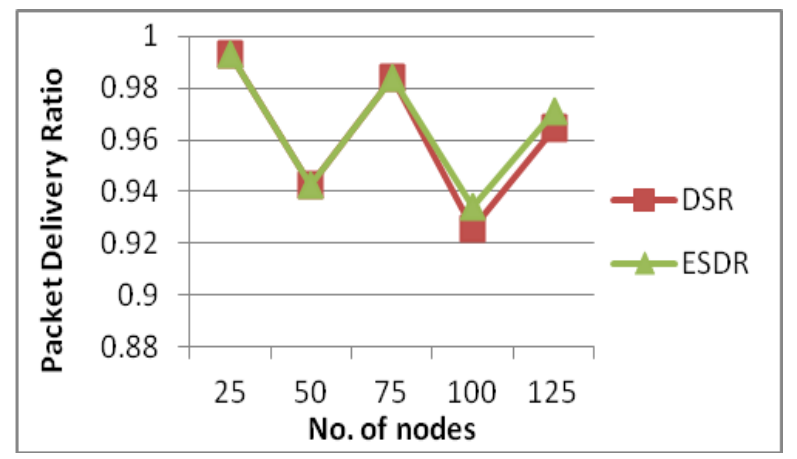

(a) Packet Delivery Ratio $\left(1000 \mathrm{~m}^{\star} 1000 \mathrm{~m}\right)$

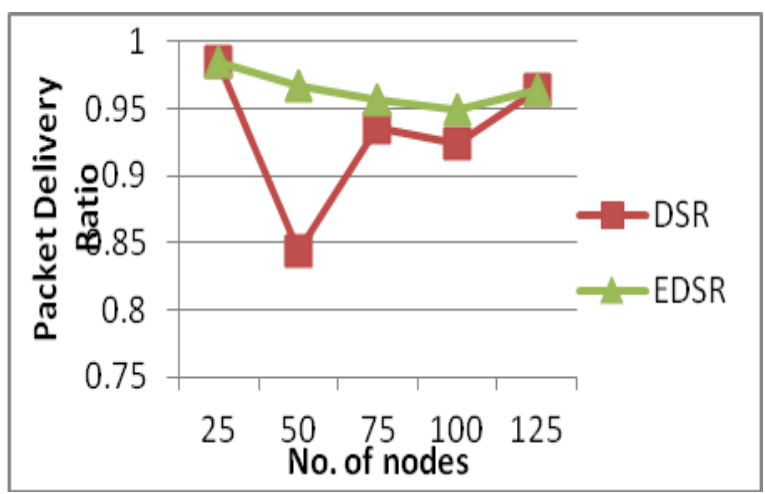

(b) Packet Delivery Ratio $\left(1500 m^{*} 1500 m\right)$ 


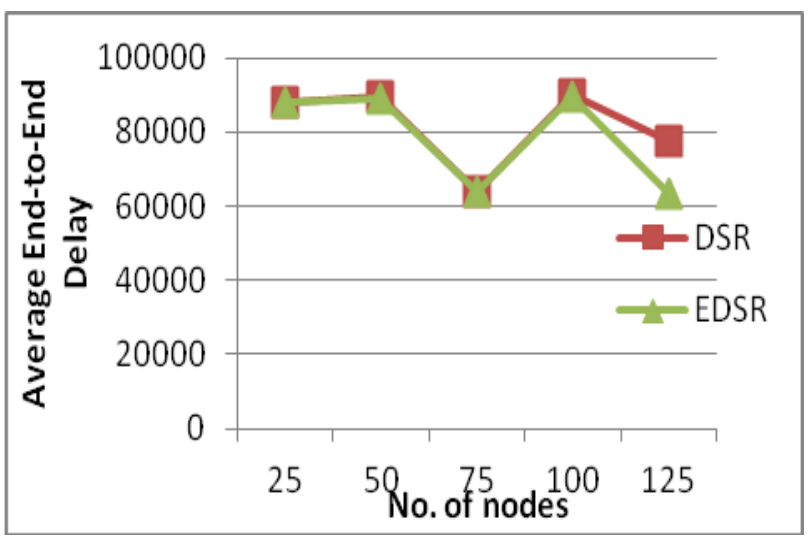

(c) Average End-to-end Delay $\left(1000 \mathrm{~m}^{*} 1000 \mathrm{~m}\right)$

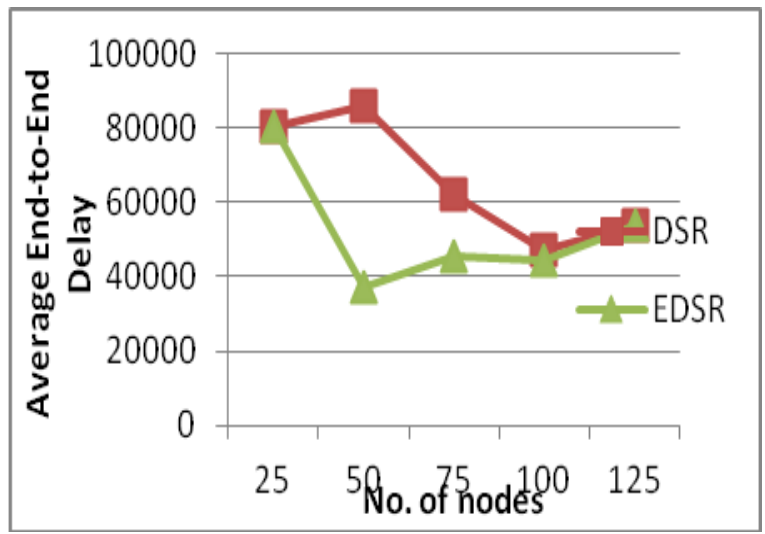

(d) Average End-to-End Delay (1500m*1500m)

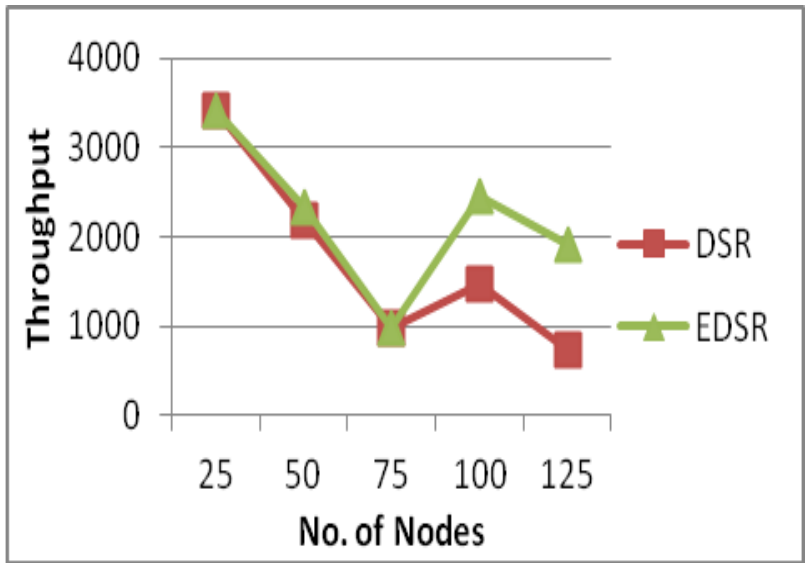

(e) Throughput $\left(1000 \mathrm{~m}^{*} 1000 \mathrm{~m}\right)$ 


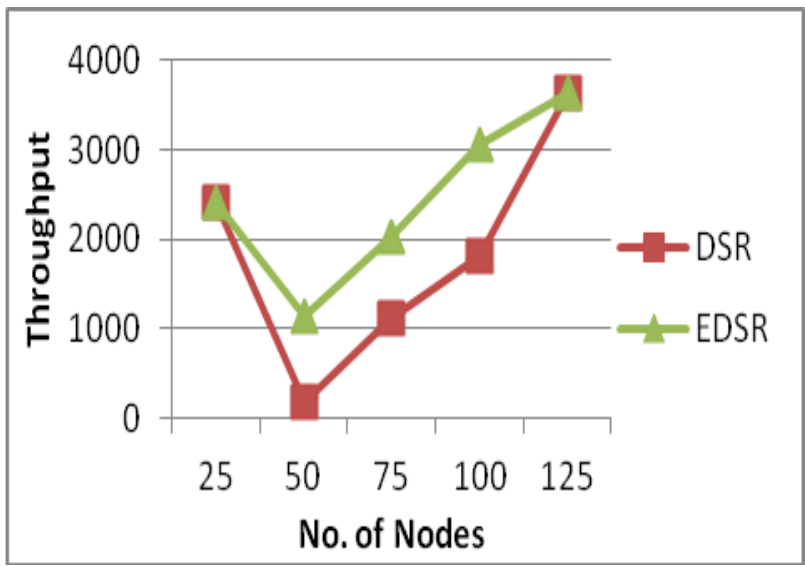

(f) Throughput $\left(1500 \mathrm{~m}^{*} 1500 \mathrm{~m}\right)$

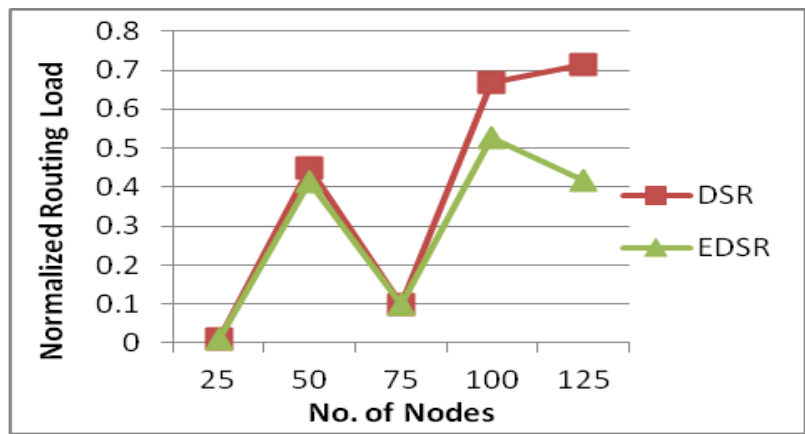

(g) Normalized Routing Load $\left(1000 m^{*} 1000 \mathrm{~m}\right)$

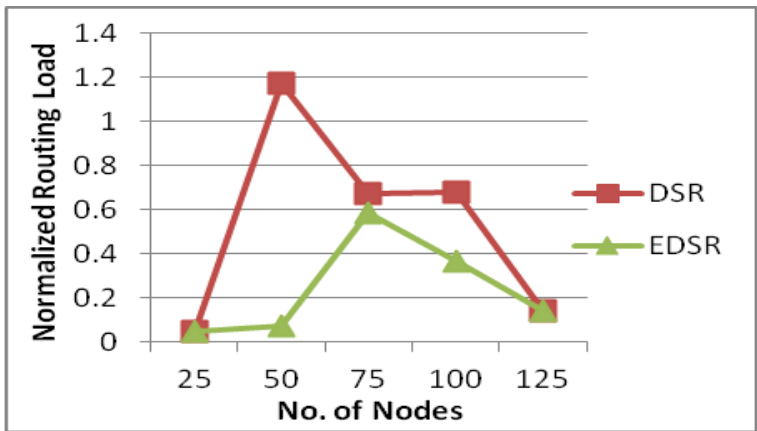

(h) Normalized Routing Load $\left(1500 m^{*} 1500 m\right)$

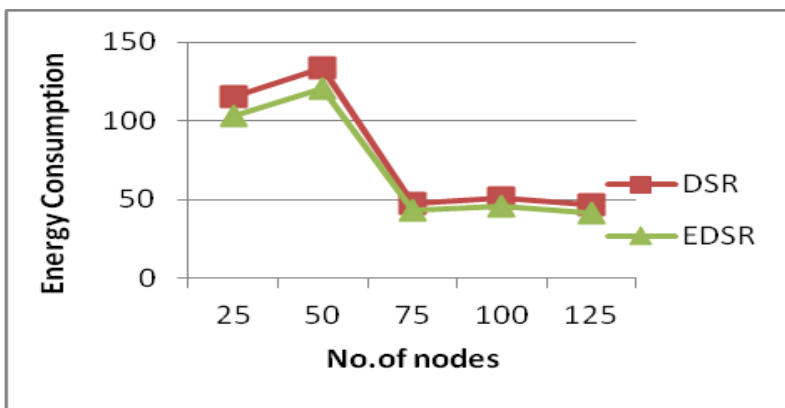

(i)Energy Consumption $\left(1000 m^{*} 1000 m\right)$ 


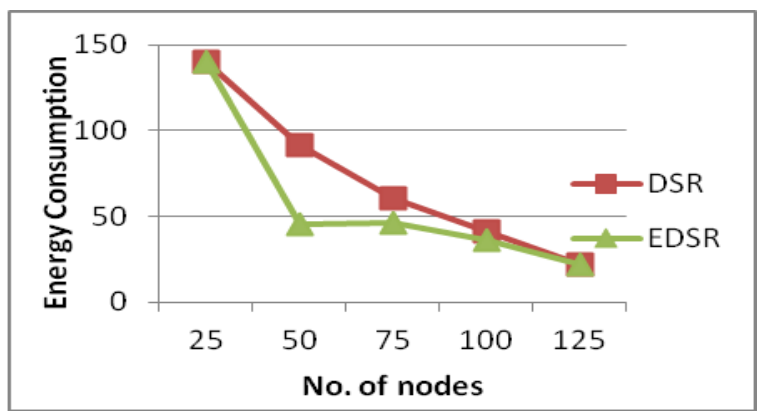

(j)Energy Consumption (1500m*1500m)

Figure 10. Performance Analysis under TCP and FTP Traffic condition by varying Number of Nodes and different network size i.e. $1000 \mathrm{~m}^{\star} 1000 \mathrm{~m}$ and $1500 \mathrm{~m}^{\star} 1500 \mathrm{~m}$ (a) Variation of Packet Delivery Ratio $\left(1000 \mathrm{~m}^{\star} 1000 \mathrm{~m}\right)(\mathrm{b})$ Variation of Packet Delivery Ratio $\left(1500 \mathrm{~m}^{\star} 1500 \mathrm{~m}\right)$ (c) Variation of Average End-to-End Delay $\left(1000 \mathrm{~m}^{\star} 1000 \mathrm{~m}\right)(\mathrm{d})$ Variation of Average End-to-End Delay $\left(1500 m^{*} 1500 \mathrm{~m}\right)(\mathrm{e})$ Variation of Throughput $\left(1000 \mathrm{~m}^{*} 1000 \mathrm{~m}\right)(\mathrm{f})$ Variation of Throughput $\left(1500 \mathrm{~m}^{\star} 1500 \mathrm{~m}\right)(\mathrm{g})$ Variation of Normalized Routing Load $\left(1000 m^{\star} 1000 \mathrm{~m}\right)(\mathrm{h})$ Variation of Normalized Routing Load $(1500 \mathrm{~m} * 1500 \mathrm{~m})(\mathrm{i})$ Variation of Energy Consumption $\left(1000 \mathrm{~m}^{*} 1000 \mathrm{~m}\right)(\mathrm{j})$ Variation of Energy Consumption $\left(1500 \mathrm{~m}^{*} 1500 \mathrm{~m}\right)$

\subsubsection{Performance Analysis under Different Network Size}

Figure10 shows the performance analysis of DSR and EDSR routing protocols under TCP and FTP traffic condition by varying number of nodes with different network size. In Figure 10 (a) the variation of Packet Delivery Ratio is shown with $1000 m^{*} 1000 \mathrm{~m}$ network size. The Packet Delivery Ratio in EDSR is much better than in DSR routing protocol. In Figure 10 (b) the variation of Packet Delivery Ratio is shown with $1500 \mathrm{~m} * 1500 \mathrm{~m}$. Again the Packet Delivery Ratio in EDSR is better than in DSR. In Figure10 (c) the variation of Average End-to-End Delay is shown with $1000 \mathrm{~m} * 1000 \mathrm{~m}$ network size. The Average End-to-End Delay in EDSR is less than in DSR routing protocol at higher number of nodes i.e. 125. In Figure10 (d) the variation of Average End-to-End Delay is shown with $1500 \mathrm{~m} * 1500 \mathrm{~m}$ network size. Again the Average End-to-End Delay in EDSR is less than in DSR routing protocol. Figure10 (e) shows the variation of throughput with $1000 \mathrm{~m} * 1000 \mathrm{~m}$ network size. The throughput in EDSR is more than in DSR routing protocol and is much better in EDSR routing protocol at higher number of nodes. Figure10 (f) shows the variation of throughput with $1500 \mathrm{~m} * 1500 \mathrm{~m}$ network size. The throughput in EDSR routing protocol is much better than in DSR routing protocol. Figure10 (g) shows the variation of Normalized Routing Load with $1000 \mathrm{~m}^{*} 1000 \mathrm{~m}$ network size. Normalized Routing Load is less in EDSR than in DSR routing protocol. Figure10 (h) shows the variation of Normalized Routing Load with $1000 \mathrm{~m} * 1000 \mathrm{~m}$ network size. Normalized Routing Load in EDSR is less than in DSR routing protocol. Figure10 (i) shows the variation of Energy Consumption with $1000 m^{*} 1000 m$ network size. Energy Consumption is less in EDSR than in DSR routing protocol. Figure10 (j) shows the variation of Energy Consumption with $1500 \mathrm{~m}^{*} 1500 \mathrm{~m}$ network size. Again Energy Consumption in EDSR is less than in DSR routing protocol. 
5.9. Performance Analysis of DSR and EDSR by varying number of nodes under UDP and CBR traffic condition with $1000 * 1000$ network size and $1500 * 1500$ network size.

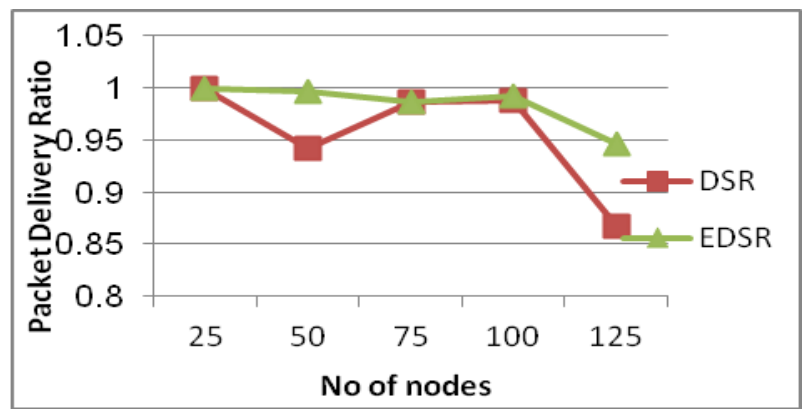

(a)Packet Delivery Ratio $\left(1000 m^{*} 1000 \mathrm{~m}\right)$

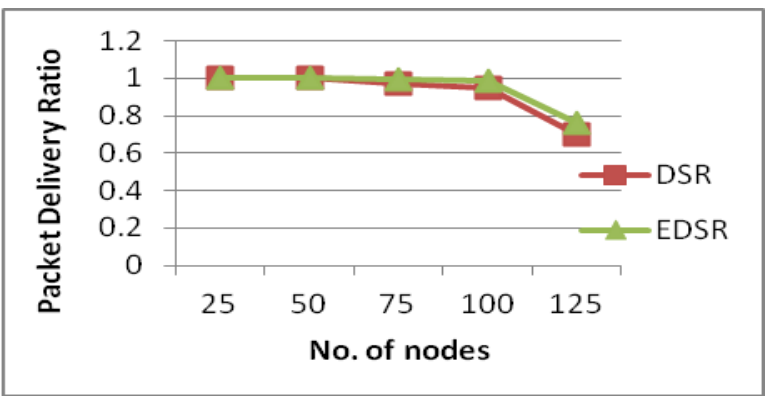

(b) Packet Delivery Ratio $\left(1500 m^{*} 1500 m\right)$

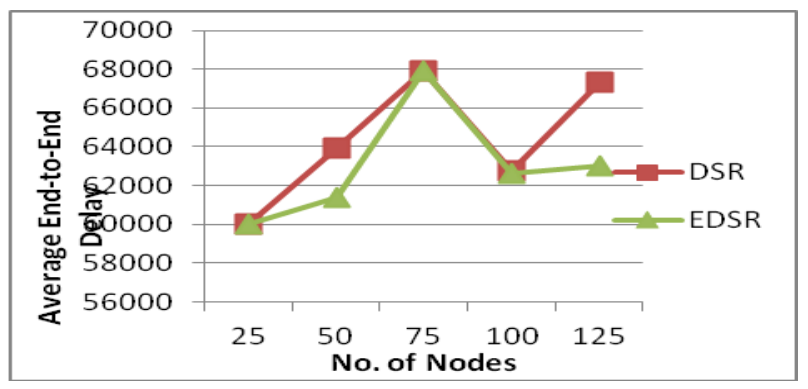

(c) Average End-to-end Delay $\left(1000 \mathrm{~m}^{*} 1000 \mathrm{~m}\right)$

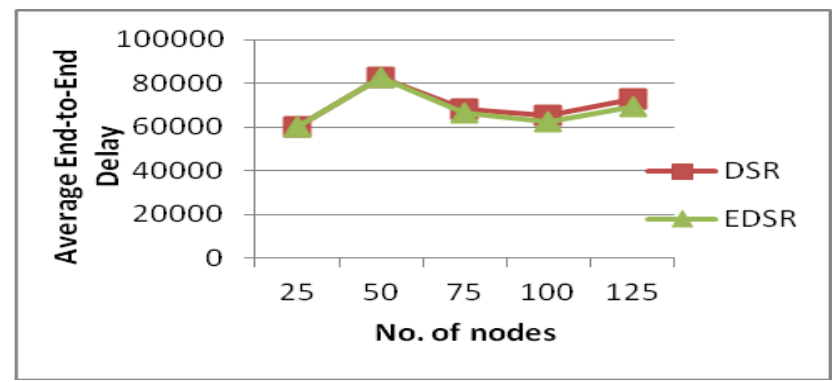

(d) Average End-to-End Delay $\left(1500 m^{*} 1500 \mathrm{~m}\right)$ 


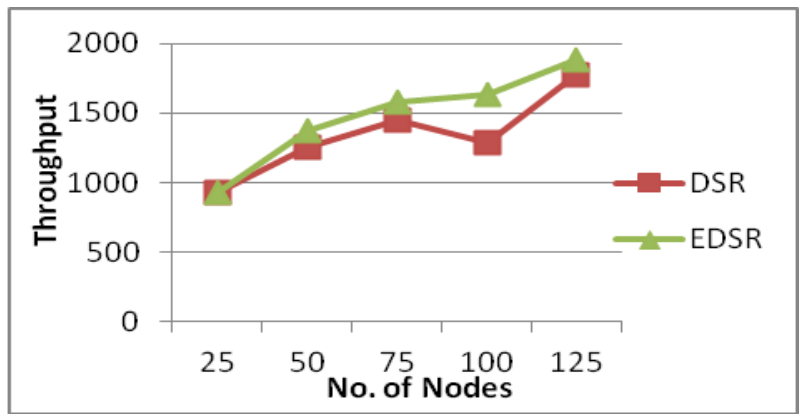

(e) Throughput $\left(1000 m^{*} 1000 m\right)$

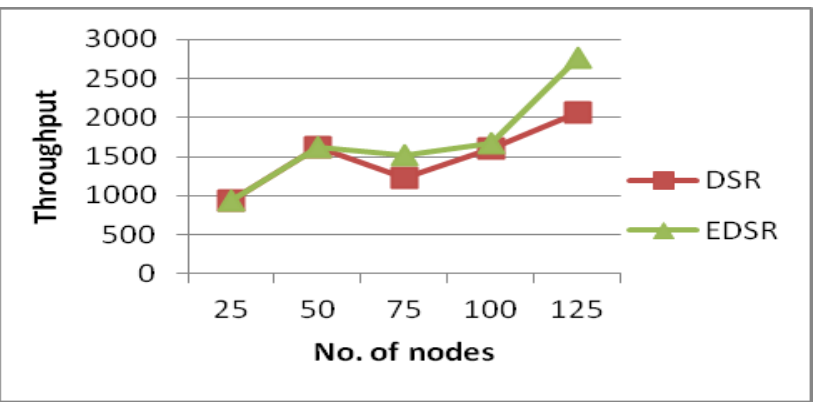

(e) Throughput $\left(1500 \mathrm{~m}^{*} 1500 \mathrm{~m}\right)$

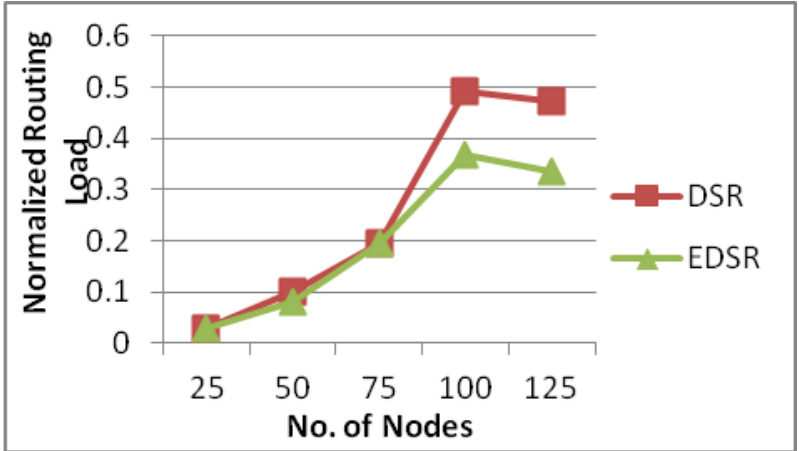

(g) Normalized Routing Load $\left(1000 m^{*} 1000 \mathrm{~m}\right)$

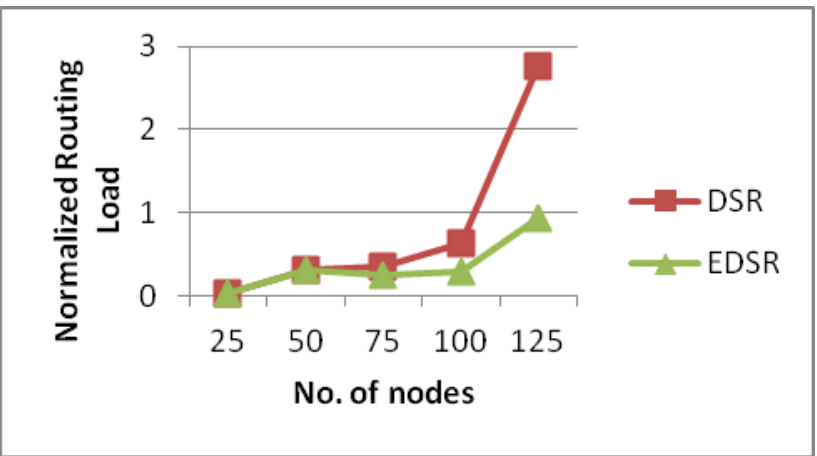

(h) Normalized Routing Load $\left(1500 m^{*} 1500 m\right.$ 


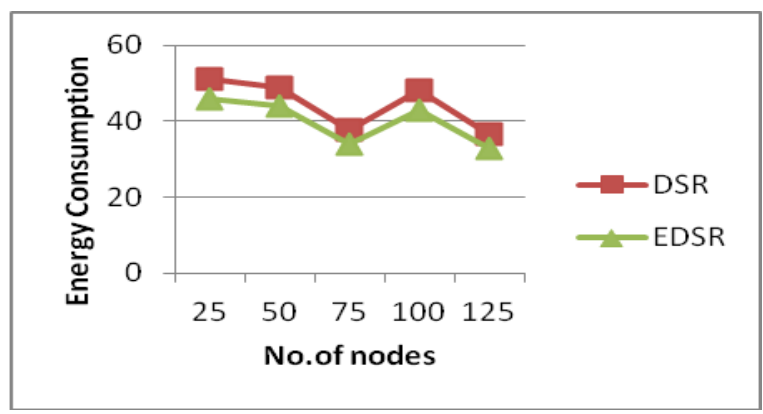

(i) Energy Consumption $\left(1000 \mathrm{~m}^{*} 1000 \mathrm{~m}\right)$

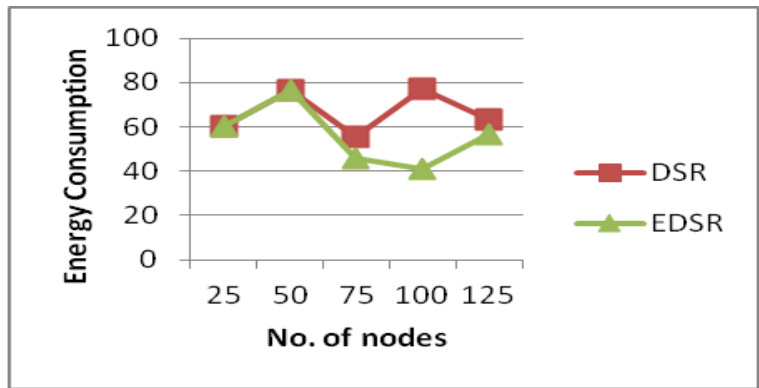

(j) Energy Consumption $\left(1500 \mathrm{~m}^{*} 1500 \mathrm{~m}\right)$

Figure11. Performance Analysis under UDP and CBR Traffic condition by varying Number of Nodes and different network size i.e. $1000 \mathrm{~m}^{*} 1000 \mathrm{~m}$ and $1500 \mathrm{~m}^{\star} 1500 \mathrm{~m}$ (a) Variation of Packet Delivery Ratio $\left(1000 \mathrm{~m}^{\star} 1000 \mathrm{~m}\right)(\mathrm{b})$ Variation of Packet Delivery Ratio $\left(1500 \mathrm{~m}^{*} 1500 \mathrm{~m}\right)$ (c) Variation of Average End-to-End Delay $\left(1000 \mathrm{~m}^{\star} 1000 \mathrm{~m}\right)(\mathrm{d})$ Variation of Average End-to-End Delay $\left(1500 \mathrm{~m}^{*} 1500 \mathrm{~m}\right)(\mathrm{e})$ Variation of Throughput $\left(1000 \mathrm{~m}^{\star} 1000 \mathrm{~m}\right)(\mathrm{f})$ Variation of Throughput $\left(1500 \mathrm{~m}^{*} 1500 \mathrm{~m}\right)(\mathrm{g})$ Variation of Normalized Routing Load $\left(1000 m^{\star} 1000 \mathrm{~m}\right)(\mathrm{h})$ Variation of Normalized Routing Load $\left(1500 \mathrm{~m}^{\star} 1500 \mathrm{~m}\right)(\mathrm{i})$ Variation of Energy Consumption $\left(1000 \mathrm{~m}^{\star} 1000 \mathrm{~m}\right)(\mathrm{j})$ Variation of Energy Consumption $\left(1500 \mathrm{~m}^{\star} 1500 \mathrm{~m}\right)$

\subsubsection{Performance Analysis under Different Network Size}

Figure11 The performance analysis of DSR and EDSR routing protocols under UDP and CBR traffic condition by varying number of nodes with different network size. In Figure 11 (a) the variation of Packet Delivery Ratio is shown with $1000 \mathrm{~m} * 1000 \mathrm{~m}$ network size. The Packet Delivery Ratio in EDSR is much better than in DSR routing protocol. In Figure11 (b) the variation of Packet Delivery Ratio is shown with $1500 m^{*} 1500 \mathrm{~m}$. Again the Packet Delivery Ratio in EDSR is better than in DSR. In Figure 11 (c) the variation of Average End-to-End Delay is shown with $1000 \mathrm{~m} * 1000 \mathrm{~m}$ network size. The Average End-to-End Delay in EDSR is less than in DSR routing protocol. In Figure11 (d) the variation of Average End-to-End Delay is shown with $1500 m^{*} 1500 \mathrm{~m}$ network size. Again the Average End-to-End Delay in EDSR is less than in DSR routing protocol. Figure11 (e) shows the variation of throughput with $1000 \mathrm{~m} * 1000 \mathrm{~m}$ network size. The throughput in EDSR is more than in DSR routing protocol. Figure11 (f) shows the variation of throughput with $1500 \mathrm{~m}^{*} 1500 \mathrm{~m}$ network size. The throughput in EDSR routing protocol is much better than in DSR routing protocol. Figure11 (g) shows the variation of Normalized Routing Load with $1000 m^{*} 1000 \mathrm{~m}$ network size. Normalized Routing Load is less in EDSR than in DSR routing protocol. Figure11 (h) shows the variation of Normalized Routing Load with $1000 m^{*} 1000 m$ network size. Normalized Routing Load in EDSR is less than in DSR 
routing protocol. Figure11 (i) shows the variation of Energy Consumption with $1000 m^{*} 1000 m$ network size. Energy Consumption is less in EDSR than in DSR routing protocol. Figure11 (j) shows the variation of Energy Consumption with $1500 \mathrm{~m}^{*} 1500 \mathrm{~m}$ network size. Energy Consumption in EDSR is less than in DSR routing protocol.

\section{Conclusion}

In this paper, multicasting technique has been proposed to enhance the performance of DSR routing protocol. The performance analysis of DSR and Enhanced DSR routing protocol is carried out by varying number of nodes under each traffic condition with 512 bytes and 1000 bytes packet size, with two ray ground and Shadowing propagation models and with $1000 \mathrm{~m}^{*} 1000 \mathrm{~m}$ and $1500 \mathrm{~m} * 1500 \mathrm{~m}$ network size. The performance metrics used to analyze the performance of DSR and EDSR routing protocols are Packet Delivery Ratio (PDR), Average End-to-End Delay, Throughput, Normalized Routing Load (NRL) and Energy Consumption. Simulation results show that the behaviour of DSR and Enhanced DSR routing protocols is different under TCP and CBR, TCP and FTP and UDP and CBR traffic conditions with 512 bytes and 1000 bytes respectively with respect to Packet Delivery Ratio (PDR), Average End-to-End Delay, Throughput, Normalized Routing Load (NRL) and Energy Consumption. The performance of Enhanced DSR routing protocol is better than DSR routing protocol with different performance metrics under every traffic condition and propagation models.

Table 2. Performance Analysis of DSR and EDSR by Varying Number of Nodes under Different Traffic Conditions with 512 Bytes Packet Size

\begin{tabular}{|c|c|c|c|c|c|c|c|c|c|c|c|c|}
\hline \multirow{7}{*}{\begin{tabular}{|l|} 
\\
\\
TC \\
$\mathbf{P}$ \\
and \\
CB \\
R \\
\end{tabular}} & \multicolumn{6}{|c|}{ DSR } & \multicolumn{6}{|c|}{$\begin{array}{l}\text { EDSR } \\
\end{array}$} \\
\hline & $\begin{array}{l}\text { No. } \\
\text { of } \\
\text { nod } \\
\text { es }\end{array}$ & PDR & Delay & $\begin{array}{l}\text { Through } \\
\text { put }\end{array}$ & $\begin{array}{l}\text { NR } \\
\mathrm{L}\end{array}$ & $\begin{array}{l}\text { Energ } \\
\mathrm{y}\end{array}$ & $\begin{array}{l}\text { No. } \\
\text { of } \\
\text { nod } \\
\text { es }\end{array}$ & PDR & Delay & $\begin{array}{l}\text { Through } \\
\text { put }\end{array}$ & $\begin{array}{l}\text { NR } \\
\mathrm{L}\end{array}$ & $\begin{array}{l}\text { Energ } \\
\mathrm{y}\end{array}$ \\
\hline & 25 & $\begin{array}{l}1.000 \\
0\end{array}$ & $\begin{array}{l}59982 \\
.6\end{array}$ & 1853.06 & $\begin{array}{l}0.01 \\
2\end{array}$ & 60 & 25 & $\begin{array}{l}1.000 \\
0\end{array}$ & $\begin{array}{l}59982 \\
.6 \\
\end{array}$ & 1853.06 & $\begin{array}{l}0.01 \\
2\end{array}$ & 54 \\
\hline & 50 & $\begin{array}{l}0.971 \\
6 \\
\end{array}$ & $\begin{array}{l}89804 \\
.7 \\
\end{array}$ & 2548.92 & $\begin{array}{l}0.74 \\
0 \\
\end{array}$ & 109.9 & 50 & $\begin{array}{l}0.977 \\
1 \\
\end{array}$ & $\begin{array}{l}89396 \\
.1 \\
\end{array}$ & 2725.65 & $\begin{array}{l}0.53 \\
2 \\
\end{array}$ & 98.9 \\
\hline & 75 & $\begin{array}{l}0.974 \\
5\end{array}$ & $\begin{array}{l}69776 \\
.8\end{array}$ & 491.46 & $\begin{array}{l}0.31 \\
3\end{array}$ & $\begin{array}{l}43.01 \\
33\end{array}$ & 75 & $\begin{array}{l}0.974 \\
5\end{array}$ & $\begin{array}{l}69776 \\
.8\end{array}$ & 491.46 & $\begin{array}{l}0.31 \\
3\end{array}$ & $\begin{array}{l}38.61 \\
33\end{array}$ \\
\hline & 100 & $\begin{array}{l}0.909 \\
0\end{array}$ & $\begin{array}{l}89819 \\
3\end{array}$ & 575.59 & $\begin{array}{l}2.18 \\
7\end{array}$ & 44.1 & 100 & $\begin{array}{l}0.974 \\
8\end{array}$ & $\begin{array}{l}79209 \\
2\end{array}$ & 878.11 & $\begin{array}{l}0.89 \\
8\end{array}$ & 44.1 \\
\hline & 125 & $\begin{array}{l}0.941 \\
7\end{array}$ & 88936 & 1649.49 & $\begin{array}{l}1.44 \\
1\end{array}$ & $\begin{array}{l}40.58 \\
4\end{array}$ & 125 & $\begin{array}{l}0.971 \\
8\end{array}$ & $\begin{array}{l}51253 \\
.4\end{array}$ & 1681.49 & $\begin{array}{l}1.00 \\
1\end{array}$ & $\begin{array}{l}36.50 \\
4\end{array}$ \\
\hline \multirow{7}{*}{$\begin{array}{l}\text { TC } \\
\text { P } \\
\text { and } \\
\text { FT } \\
\text { P }\end{array}$} & \multicolumn{6}{|c|}{ DSR } & \multicolumn{6}{|c|}{$\begin{array}{c}\text { EDSR } \\
\end{array}$} \\
\hline & $\begin{array}{l}\text { No. } \\
\text { of } \\
\text { node } \\
\text { s }\end{array}$ & PDR & Delay & $\begin{array}{l}\text { Throughp } \\
\text { ut }\end{array}$ & $\begin{array}{l}\text { NR } \\
\mathrm{L}\end{array}$ & $\begin{array}{l}\text { Energ } \\
\mathrm{y}\end{array}$ & $\begin{array}{l}\text { No. } \\
\text { of } \\
\text { node } \\
\text { s }\end{array}$ & PDR & Delay & $\begin{array}{l}\text { Throughp } \\
\text { ut }\end{array}$ & $\begin{array}{l}\text { NR } \\
\mathrm{L}\end{array}$ & $\begin{array}{l}\text { Energ } \\
\text { y }\end{array}$ \\
\hline & 25 & $\begin{array}{l}0.993 \\
0\end{array}$ & $\begin{array}{l}88032 . \\
6\end{array}$ & 3405.24 & $\begin{array}{l}0.01 \\
2\end{array}$ & $\begin{array}{l}115.0 \\
4\end{array}$ & 25 & $\begin{array}{l}0.993 \\
0\end{array}$ & $\begin{array}{l}88032 . \\
6\end{array}$ & 3405.24 & $\begin{array}{l}0.01 \\
2\end{array}$ & $\begin{array}{l}103.4 \\
4\end{array}$ \\
\hline & 50 & $\begin{array}{l}0.942 \\
3\end{array}$ & $\begin{array}{l}89770 . \\
1\end{array}$ & 2194.95 & $\begin{array}{l}0.44 \\
9\end{array}$ & $\begin{array}{l}133.7 \\
2\end{array}$ & 50 & $\begin{array}{l}0.942 \\
8 \\
\end{array}$ & $\begin{array}{l}89281 . \\
1\end{array}$ & 2336.81 & $\begin{array}{l}0.41 \\
5\end{array}$ & $\begin{array}{l}120.3 \\
2\end{array}$ \\
\hline & 75 & $\begin{array}{l}0.983 \\
9\end{array}$ & $\begin{array}{l}63822 . \\
5\end{array}$ & 972.04 & $\begin{array}{l}0.10 \\
0\end{array}$ & 48 & 75 & $\begin{array}{l}0.983 \\
9\end{array}$ & $\begin{array}{l}63822 . \\
5\end{array}$ & 972.04 & $\begin{array}{l}0.10 \\
0\end{array}$ & 43.2 \\
\hline & 100 & $\begin{array}{l}0.925 \\
4\end{array}$ & 89992 & 1473.87 & $\begin{array}{l}0.66 \\
8\end{array}$ & 50.78 & 100 & $\begin{array}{l}0.934 \\
1\end{array}$ & $\begin{array}{l}89663 . \\
9\end{array}$ & 2445.79 & $\begin{array}{l}0.52 \\
7\end{array}$ & 45.68 \\
\hline & 125 & $\begin{array}{l}0.964 \\
3\end{array}$ & $\begin{array}{l}77707 . \\
3 \\
\end{array}$ & 736.91 & $\begin{array}{l}0.71 \\
5 \\
\end{array}$ & $\begin{array}{l}46.37 \\
6 \\
\end{array}$ & 125 & $\begin{array}{l}0.971 \\
0 \\
\end{array}$ & $\begin{array}{l}63311 . \\
5\end{array}$ & 1923.49 & $\begin{array}{l}0.41 \\
7 \\
\end{array}$ & $\begin{array}{l}41.65 \\
6 \\
\end{array}$ \\
\hline \multirow{7}{*}{$\begin{array}{l}\text { UD } \\
\text { P } \\
\text { and } \\
\text { CB } \\
R\end{array}$} & \multicolumn{6}{|c|}{ DSR } & \multicolumn{6}{|c|}{ EDSR } \\
\hline & $\begin{array}{l}\text { No. } \\
\text { of } \\
\text { node } \\
\text { s }\end{array}$ & PDR & Delay & $\begin{array}{l}\text { Throughp } \\
\text { ut }\end{array}$ & $\begin{array}{l}\text { NR } \\
\mathrm{L}\end{array}$ & $\begin{array}{l}\text { Energ } \\
\mathrm{y}\end{array}$ & $\begin{array}{l}\text { No. } \\
\text { of } \\
\text { nod } \\
\text { es }\end{array}$ & PDR & Delay & $\begin{array}{l}\text { Through } \\
\text { put }\end{array}$ & $\begin{array}{l}\text { NR } \\
\mathrm{L}\end{array}$ & $\begin{array}{l}\text { Energ } \\
y\end{array}$ \\
\hline & 25 & $\begin{array}{l}1.000 \\
0\end{array}$ & $\begin{array}{l}60010 . \\
8\end{array}$ & 924.79 & $\begin{array}{l}0.02 \\
8\end{array}$ & 51.04 & 25 & $\begin{array}{l}1.000 \\
0\end{array}$ & $\begin{array}{l}60010 \\
8\end{array}$ & 924.79 & $\begin{array}{l}0.02 \\
8\end{array}$ & 45.84 \\
\hline & 50 & $\begin{array}{l}0.941 \\
8 \\
\end{array}$ & 63955 & 1251.86 & $\begin{array}{l}0.10 \\
2\end{array}$ & 49.02 & 50 & $\begin{array}{l}0.996 \\
2\end{array}$ & $\begin{array}{l}61380 \\
2\end{array}$ & 1274.43 & 0.08 & 44.02 \\
\hline & 75 & $\begin{array}{l}0.985 \\
9\end{array}$ & 67911 & 1451.79 & $\begin{array}{l}0.19 \\
5\end{array}$ & 37.68 & 75 & $\begin{array}{l}0.985 \\
9\end{array}$ & 67911 & 1451.79 & $\begin{array}{l}0.19 \\
5\end{array}$ & $\begin{array}{l}33.81 \\
33\end{array}$ \\
\hline & 100 & $\begin{array}{l}0.988 \\
0\end{array}$ & $\begin{array}{l}62767 . \\
3 \\
\end{array}$ & 1283.79 & $\begin{array}{l}0.49 \\
3 \\
\end{array}$ & 48.01 & 100 & $\begin{array}{l}0.992 \\
5 \\
\end{array}$ & $\begin{array}{l}62657 \\
2 \\
\end{array}$ & 1329.68 & $\begin{array}{l}0.36 \\
7 \\
\end{array}$ & 43.11 \\
\hline & 125 & $\begin{array}{l}0.867 \\
5\end{array}$ & $\begin{array}{l}67349 . \\
1\end{array}$ & 1769.47 & $\begin{array}{l}0.47 \\
4 \\
\end{array}$ & $\begin{array}{l}36.60 \\
8\end{array}$ & 125 & $\begin{array}{l}0.946 \\
4 \\
\end{array}$ & $\begin{array}{l}62996 \\
.4\end{array}$ & 1882.46 & $\begin{array}{l}0.33 \\
5\end{array}$ & $\begin{array}{l}32.84 \\
8 \\
\end{array}$ \\
\hline
\end{tabular}


Table 3. Performance Analysis of DSR and EDSR by Varying Number of Nodes under Different Traffic Conditions with 1000 Bytes Packet Size

\begin{tabular}{|c|c|c|c|c|c|c|c|c|c|c|c|}
\hline \multirow{7}{*}{$\begin{array}{l}\text { TCP } \\
\text { and } \\
\text { CBR }\end{array}$} & \multicolumn{6}{|c|}{ DSR } & \multicolumn{5}{|c|}{ EDSR } \\
\hline & $\begin{array}{l}\text { No. } \\
\text { of } \\
\text { nodes }\end{array}$ & PDR & Delay & Throughput & NRL & Energy & $\begin{array}{l}\text { No. } \\
\text { of } \\
\text { nodes }\end{array}$ & PDR & Delay & Throughput & NRL \\
\hline & 25 & 0.9990 & 60960.2 & 943.47 & 0.039 & 84 & 25 & 0.9990 & 60960.2 & 943.47 & 0.039 \\
\hline & 50 & 0.9396 & 76094.3 & 364.86 & 0.529 & 82 & 50 & 0.9772 & 70809.6 & 1483.80 & 0.400 \\
\hline & 75 & 0.9116 & 89617.1 & 198.41 & 1.882 & 51.0133 & 75 & 0.9116 & 71180.7 & 251.22 & 1.785 \\
\hline & 100 & 0.9532 & 62767 & 181.89 & 0.743 & 30.02 & 100 & 0.9639 & 53679.7 & 994.96 & 0.719 \\
\hline & 125 & 0.9544 & 49785.4 & 921.40 & 0.663 & 24.496 & 125 & 0.9544 & 49785.4 & 921.40 & 0.663 \\
\hline & & & & DSR & & & & & & DSR & \\
\hline TCP & $\begin{array}{l}\text { No. } \\
\text { of } \\
\text { nodes }\end{array}$ & PDR & Delay & Throughput & NRL & Energy & $\begin{array}{l}\text { No. } \\
\text { of } \\
\text { nodes }\end{array}$ & PDR & Delay & Throughput & NRL \\
\hline and & 25 & 0.9930 & 88032.6 & 3325.20 & 0.012 & 115.04 & 25 & 0.9930 & 88032.6 & 3325.20 & 0.012 \\
\hline FTP & 50 & 0.9423 & 89770.1 & 2142.66 & 0.449 & 133.72 & 50 & 0.9428 & 89281.1 & 2279.73 & 0.415 \\
\hline & 75 & 0.9839 & 63822.5 & 947.45 & 0.100 & 48 & 75 & 0.9839 & 63822.5 & 947.45 & 0.100 \\
\hline & 100 & 0.9254 & 89992 & 1436.97 & 0.668 & 50.78 & 100 & 0.9341 & 89663.9 & 2385.36 & 0.527 \\
\hline & 125 & 0.9643 & 77707.3 & 717.00 & 0.715 & 46.376 & 125 & 0.9710 & 63311.5 & 1868.08 & 0.417 \\
\hline & & & & DSR & & & & & & DSR & \\
\hline UDP & $\begin{array}{l}\text { No. } \\
\text { of } \\
\text { nodes }\end{array}$ & PDR & Delay & Throughput & NRL & Energy & $\begin{array}{l}\text { No. } \\
\text { of } \\
\text { nodes }\end{array}$ & PDR & Delay & Throughput & NRL \\
\hline and & 25 & 1.0000 & 59964.1 & 958.36 & 0.049 & 51.04 & 25 & 1.0000 & 59964.1 & 958.36 & 0.049 \\
\hline CBR & 50 & 0.8560 & 86513.9 & 1170.97 & 0.382 & 53.02 & 50 & 0.9555 & 66458.5 & 1619.40 & 0.300 \\
\hline & 75 & 0.9802 & 66905.6 & 1212.92 & 0.500 & 43.0133 & 75 & 0.9876 & 66843.6 & 1214.10 & 0.279 \\
\hline & 100 & 0.9807 & 62657.2 & 1319.31 & 0.775 & 48.01 & 100 & 0.9880 & 62572.2 & 1327.47 & 0.583 \\
\hline & 125 & 0.9464 & 62996.4 & 1868.49 & 1.005 & 42.208 & 125 & 0.9610 & 62919.7 & 2281.25 & 0.723 \\
\hline
\end{tabular}

Table 4. Performance Analysis of DSR and EDSR By Varying Number of Nodes Under Different Traffic Conditions and Two Ray Ground Propagation Model

\begin{tabular}{|c|c|c|c|c|c|c|c|c|c|c|}
\hline \multirow{8}{*}{$\begin{array}{r}\text { TCP } \\
\text { and } C B R\end{array}$} & \multicolumn{6}{|c|}{ DSR } & \multicolumn{4}{|c|}{ EDSR } \\
\hline & $\begin{array}{l}\text { No. of } \\
\text { nodes }\end{array}$ & PDR & Delay & Throughput & NRL & Energy & \multirow{2}{*}{$\begin{array}{l}\text { No. } \\
\text { of } \\
\text { nodes }\end{array}$} & \multirow[t]{2}{*}{$\begin{array}{l}\mathrm{PDR} \\
\end{array}$} & \multirow[t]{2}{*}{ Delay } & \multirow[t]{2}{*}{ Throug hput } \\
\hline & 25 & 1.0000 & 59982.6 & 1853.06 & 0.012 & 60 & & & & \\
\hline & 50 & 0.9716 & 89804.7 & 2548.92 & 0.740 & 109.9 & 25 & 1.0000 & 59982.6 & 1853.06 \\
\hline & 75 & 0.9745 & 69776.8 & 491.46 & 0.313 & 43.0133 & 50 & 0.9771 & 89396.1 & 2725.65 \\
\hline & 100 & 0.9090 & 89819.3 & 575.59 & 2.187 & 44.1 & 75 & 0.9745 & 69776.8 & 491.46 \\
\hline & 125 & 0.9417 & 88936 & 1649.49 & 1.441 & 40.584 & 100 & 0.9748 & 79209.2 & 878.11 \\
\hline & & & & & & & 125 & 0.9718 & 51253.4 & 1681.49 \\
\hline \multirow{9}{*}{$\begin{array}{r}\text { TCP } \\
\text { and FTP }\end{array}$} & \multicolumn{6}{|c|}{ DSR } & \multirow{3}{*}{$\begin{array}{l}\text { No. } \\
\text { of } \\
\text { nodes }\end{array}$} & & \multicolumn{2}{|c|}{ EDSR } \\
\hline & $\begin{array}{l}\text { No. of } \\
\text { nodes }\end{array}$ & PDR & Delay & Throug hput & NRL & Energy & & \multirow[t]{2}{*}{$\overline{\text { PDR }}$} & Delay & \multirow[t]{2}{*}{ Throughput } \\
\hline & 25 & 0.9930 & 88032.6 & 3405.24 & 0.012 & 115.04 & & & & \\
\hline & 50 & 0.9423 & 89770.1 & 2194.95 & 0.449 & 133.72 & 25 & 1.0000 & 59982.6 & 3405.24 \\
\hline & 75 & 0.9839 & 63822.5 & 972.04 & 0.100 & 48 & 50 & 0.9771 & 89804.7 & 2336.81 \\
\hline & 100 & 0.9254 & 89992 & 1473.87 & 0.668 & 50.78 & 75 & 0.9745 & 69776.8 & 972.04 \\
\hline & 125 & 0.9643 & 77707.3 & 736.91 & 0.715 & 46.376 & 100 & 0.9341 & 89663.9 & 2445.79 \\
\hline & & & & & & & 125 & 0.9718 & 51253.4 & 1923.49 \\
\hline & \multicolumn{6}{|c|}{ DSR } & \multirow{3}{*}{$\begin{array}{l}\text { No. } \\
\text { of } \\
\text { nodes }\end{array}$} & & \multicolumn{2}{|c|}{ EDSR } \\
\hline \multirow{7}{*}{$\begin{array}{r}\text { UDP } \\
\text { and CBR }\end{array}$} & $\begin{array}{l}\text { No. of } \\
\text { nodes }\end{array}$ & PDR & Delay & Throug hput & NRL & Energy & & PDR & Delay & \multirow[t]{2}{*}{ Throug hput } \\
\hline & 25 & 1.0000 & 60010.8 & 924.79 & 0.028 & 51.04 & & & & \\
\hline & 50 & 0.9418 & 63955 & 1251.86 & 0.102 & 49.02 & 25 & 1.0000 & 60010.8 & 924.79 \\
\hline & 75 & 0.9859 & 67911 & 1451.79 & 0.195 & 37.68 & 50 & 0.9962 & 61380.2 & 1274.43 \\
\hline & 100 & 0.9880 & 62767.3 & 1283.79 & 0.493 & 48.01 & 75 & 0.9859 & 67911 & 1451.79 \\
\hline & 125 & 0.8675 & 67349.1 & 1769.47 & 0.474 & 36.608 & 100 & 0.9925 & 62657.2 & 1329.68 \\
\hline & & & & & & & 125 & 0.9464 & 62996.4 & 1882.46 \\
\hline
\end{tabular}


Table 5. Performance Analysis of DSR and EDSR by Varying Number of Nodes under Different Traffic Conditions and Shadowing Propagation Model

\begin{tabular}{|c|c|c|c|c|c|c|c|c|c|c|c|c|}
\hline \multirow{13}{*}{$\begin{array}{l} \\
\text { TCP } \\
\text { and } \\
\text { CB } \\
\text { R }\end{array}$} & \multicolumn{6}{|c|}{ DSR } & \multicolumn{6}{|c|}{ E DSR } \\
\hline & \multirow{3}{*}{$\begin{array}{l}\text { No. } \\
\text { of } \\
\text { nodes }\end{array}$} & \multirow[t]{3}{*}{ PDR } & \multirow[t]{3}{*}{ Delay } & \multirow[t]{3}{*}{ Throughput } & \multirow[t]{3}{*}{ NRL } & \multirow[t]{3}{*}{ Energy } & No. & PDR & Delay & Throughput & NRL & Energy \\
\hline & & & & & & & nodes & & & & & \\
\hline & & & & & & & 25 & 0.9775 & 87824.2 & 1596.91 & 0.340 & 139.64 \\
\hline & \multirow[t]{2}{*}{25} & \multirow[t]{2}{*}{0.9768} & \multirow[t]{2}{*}{88772.1} & \multirow[t]{2}{*}{1588.40} & \multirow[t]{2}{*}{0.361} & \multirow[t]{2}{*}{156} & & & & & & \\
\hline & & & & & & & 50 & 0.9718 & 56286.5 & 1811.32 & 1.062 & 62.3 \\
\hline & \multirow[t]{2}{*}{50} & \multirow[t]{2}{*}{0.9670} & \multirow[t]{2}{*}{83423.5} & \multirow[t]{2}{*}{1480.06} & \multirow[t]{2}{*}{1.324} & \multirow[t]{2}{*}{61.64} & & & & & & \\
\hline & & & & & & & 75 & 0.9256 & 73334.7 & 687.66 & 9.005 & 51.6 \\
\hline & \multirow[t]{2}{*}{75} & \multirow[t]{2}{*}{0.9144} & \multirow[t]{2}{*}{84059.7} & \multirow[t]{2}{*}{517.85} & \multirow[t]{2}{*}{9.404} & \multirow[t]{2}{*}{48.4} & & & & & & \\
\hline & & & & & & & 100 & 0.9396 & 64547.2 & 975.90 & 2.012 & 27.52 \\
\hline & \multirow[t]{2}{*}{100} & 0.9396 & 64547.2 & 975.90 & 2.012 & 30.62 & & & & & & \\
\hline & & & & & & & 125 & 0.9269 & 43815.1 & 942.59 & 5.062 & 23.424 \\
\hline & 125 & 0.9194 & 49382.6 & 792.78 & 6.054 & 31 & & & & & & \\
\hline & & & & DSR & & & & & & DSR & & \\
\hline & No. & PDR & Delay & Throughpu & NRL & Energy & No. & PDR & Delay & Throughput & NRL & Energy \\
\hline $\begin{array}{l}\text { TCP } \\
\text { and }\end{array}$ & $\begin{array}{l}\text { of } \\
\text { node }\end{array}$ & & & & & & $\begin{array}{l}\text { of } \\
\text { nodes }\end{array}$ & & & & & \\
\hline FTP & 25 & 0.974 & 89355. & 1568.96 & 0.297 & 164 & 25 & 0.9809 & 87615.1 & 1610.82 & 0.259 & 146.88 \\
\hline & & 7 & & & & & & & & & & \\
\hline & 50 & $\begin{array}{l}0.874 \\
1\end{array}$ & $\begin{array}{l}84481 . \\
4\end{array}$ & 202.14 & 2.919 & 109.02 & 50 & 0.9094 & 82693.4 & 203.48 & 1.884 & 76.54 \\
\hline & 75 & $\begin{array}{l}0.887 \\
3\end{array}$ & 71807 & 490.61 & 2.379 & $\begin{array}{l}46.666 \\
7\end{array}$ & 75 & 0.8873 & 71807 & 490.61 & 2.379 & 42 \\
\hline & 100 & $\begin{array}{l}0.866 \\
7\end{array}$ & $\begin{array}{l}54835 . \\
5\end{array}$ & 172.46 & 1.006 & 32.7 & 100 & 0.8672 & 54460.3 & 1089.60 & 0.761 & 25.74 \\
\hline & 125 & $\begin{array}{l}0.909 \\
1\end{array}$ & $\begin{array}{l}73610 . \\
3\end{array}$ & 1200.06 & $\begin{array}{l}193.82 \\
5\end{array}$ & 63.064 & 125 & 0.9104 & 54401.4 & 3397.53 & 1.082 & 35.28 \\
\hline & & & & $\overline{\mathrm{DSR}}$ & & & & & & $\overline{\mathrm{DSR}}$ & & \\
\hline & $\begin{array}{l}\text { No. } \\
\text { of }\end{array}$ & PDR & Delay & $\begin{array}{l}\text { Throughpu } \\
\mathrm{t}\end{array}$ & NRL & Energy & $\begin{array}{l}\text { No. } \\
\text { of }\end{array}$ & PDR & Delay & $\begin{array}{l}\text { Throughpu } \\
t\end{array}$ & NRI & $\begin{array}{l}\text { Energ } \\
\mathrm{y}\end{array}$ \\
\hline P & $\begin{array}{l}\text { node } \\
\text { s }\end{array}$ & & & & & & $\begin{array}{l}\text { node } \\
s\end{array}$ & & & & & \\
\hline $\begin{array}{l}\text { and } \\
C B\end{array}$ & 25 & $\begin{array}{l}0.987 \\
0\end{array}$ & $\begin{array}{l}68462 . \\
7\end{array}$ & 1174.39 & 0.197 & 107.52 & 25 & $\begin{array}{l}0.987 \\
0\end{array}$ & $\begin{array}{l}68462 . \\
7\end{array}$ & 1174.39 & 0.197 & 96.72 \\
\hline & 50 & $\begin{array}{l}0.071 \\
4\end{array}$ & $\begin{array}{l}89993 . \\
5\end{array}$ & 905.15 & $\begin{array}{l}136.00 \\
8\end{array}$ & 189.82 & 50 & $\begin{array}{l}0.375 \\
4\end{array}$ & $\begin{array}{l}89288 . \\
6\end{array}$ & 1388.30 & 6.820 & 80.4 \\
\hline & 75 & $\begin{array}{l}0.169 \\
2\end{array}$ & 89459 & 1533.96 & 18.416 & $\begin{array}{l}87.906 \\
7\end{array}$ & 75 & $\begin{array}{l}0.580 \\
0\end{array}$ & $\begin{array}{l}84624 . \\
4\end{array}$ & 2183.64 & 5.131 & 41.56 \\
\hline & 100 & $\begin{array}{l}0.077 \\
5\end{array}$ & $\begin{array}{l}90016 . \\
3\end{array}$ & 1266.31 & $\begin{array}{l}414.88 \\
2\end{array}$ & 75.63 & 100 & $\begin{array}{l}0.330 \\
8\end{array}$ & $\begin{array}{l}74171 . \\
2\end{array}$ & 1979.97 & 17.922 & 61.11 \\
\hline & 125 & $\begin{array}{l}0.086 \\
5\end{array}$ & $\begin{array}{l}89401 . \\
1\end{array}$ & 1508.24 & $\begin{array}{l}140.16 \\
1\end{array}$ & 50.264 & 125 & $\begin{array}{l}0.095 \\
0\end{array}$ & $\begin{array}{l}86733 . \\
1\end{array}$ & 1820.94 & $\begin{array}{l}123.05 \\
5\end{array}$ & 46.496 \\
\hline
\end{tabular}


Table 6. Performance Analysis of DSR and EDSR by varying Number of nodes under Different Traffic Conditions with 1500*1500 Network Size

\begin{tabular}{|c|c|c|c|c|c|c|c|c|c|c|c|c|}
\hline \multirow{8}{*}{$\begin{array}{l}\text { TCP } \\
\text { and } \\
\text { CB } \\
\text { R }\end{array}$} & \multicolumn{6}{|c|}{ DSR } & \multicolumn{6}{|c|}{ E DSR } \\
\hline & $\begin{array}{l}\text { No. } \\
\text { of } \\
\text { nodes }\end{array}$ & PDR & Delay & Throughput & NRL & Energy & $\begin{array}{l}\text { No. } \\
\text { of } \\
\text { nodes }\end{array}$ & PDR & Delay & Throughput & NRL & Energy \\
\hline & 25 & 0.9957 & 75052 & 1870.26 & 0.063 & 97.2 & 25 & 0.9957 & 74969.5 & 1873.90 & 0.057 & 97.2 \\
\hline & 50 & 0.9716 & 89804.7 & 2548.92 & 0.740 & 98.9 & 50 & 0.9662 & 89396.1 & 2725.65 & 0.492 & 87.7 \\
\hline & 75 & 0.9231 & 89453.2 & 1368.29 & 1.006 & 89.0133 & 75 & 0.9464 & 76281.8 & 1885.22 & 0.762 & 61.1333 \\
\hline & 100 & 0.9089 & 44863.7 & 1424.40 & 1.962 & 43.2 & 100 & 0.9544 & 39198.5 & 2303.85 & 0.551 & 29.7 \\
\hline & 125 & 0.9649 & 45050.6 & 1115.22 & 1.205 & 24.864 & & & & & & \\
\hline & & & & & & & 125 & 0.9653 & 43465 & 1753.95 & 0.902 & 23.76 \\
\hline \multirow{7}{*}{$\begin{array}{l}\text { TCP } \\
\text { and } \\
\text { FTP }\end{array}$} & \multicolumn{6}{|c|}{ DSR } & \multicolumn{6}{|c|}{ E DSR } \\
\hline & $\begin{array}{l}\text { No. } \\
\text { of } \\
\text { nodes }\end{array}$ & PDR & Delay & Throughput & NRL & Energy & $\begin{array}{l}\text { No. } \\
\text { of } \\
\text { nodes }\end{array}$ & PDR & Delay & Throughput & NRL & Energy \\
\hline & 25 & 0.9853 & 80728.5 & 2409.80 & 0.047 & 140 & 25 & 0.9853 & 80728.5 & 2409.80 & 0.047 & 140 \\
\hline & 50 & 0.8440 & 86252.9 & 173.22 & 1.175 & 91.8 & 50 & 0.9671 & 36985.5 & 1146.88 & 0.071 & 45 \\
\hline & 75 & 0.9354 & 62297.9 & 1105.41 & 0.672 & 60.3333 & 75 & 0.9569 & 45718.9 & 2036.32 & 0.587 & 46.1733 \\
\hline & 100 & 0.9243 & 47139.6 & 1805.50 & 0.677 & 41.47 & 100 & 0.9487 & 44481.4 & 3062.82 & 0.369 & 36.18 \\
\hline & 125 & 0.9637 & 53897.9 & 3626.79 & 0.141 & 22.32 & 125 & 0.9637 & 53897.9 & 3626.79 & 0.141 & 22.32 \\
\hline \multirow{7}{*}{$\begin{array}{c}\text { UDP } \\
\text { and } \\
\text { CB } \\
\mathrm{R}\end{array}$} & \multicolumn{6}{|c|}{ DSR } & \multicolumn{6}{|c|}{ E DSR } \\
\hline & $\begin{array}{l}\text { No. } \\
\text { of } \\
\text { nodes }\end{array}$ & PDR & Delay & Throughput & NRL & Energy & $\begin{array}{l}\text { No. } \\
\text { of } \\
\text { nodes }\end{array}$ & PDR & Delay & Throughput & NRL & Energy \\
\hline & 25 & 1.0000 & 60077.3 & 931.05 & 0.036 & 60.24 & 25 & 1.0000 & 60077.3 & 931.05 & 0.036 & 60.24 \\
\hline & 50 & 0.9984 & 82703.5 & 1627.89 & 0.312 & 76.42 & 50 & 0.9984 & 82703.5 & 1627.89 & 0.312 & 76.42 \\
\hline & 75 & 0.9679 & 68189.1 & 1228.92 & 0.349 & 55.4133 & 75 & 0.9913 & 66748.9 & 1526.05 & 0.252 & 45.8133 \\
\hline & 100 & 0.9471 & 65228.9 & 1605.96 & 0.621 & 77.31 & 100 & 0.9844 & 62238.8 & 1673.13 & 0.299 & 41.31 \\
\hline & 125 & 0.7010 & 73039.9 & 2068.71 & 2.757 & 63.088 & 125 & 0.7579 & 69432.1 & 2771.33 & 0.936 & 56.608 \\
\hline
\end{tabular}

DSR and Enhanced DSR routing protocols are behave differently under Two ray ground and Shadowing propagation models and under $1000 \mathrm{~m} * 1000 \mathrm{~m}$ and $1500 \mathrm{~m} * 1500 \mathrm{~m}$ network sizes. It has been concluded that the performance of Enhanced DSR routing protocol is better than the DSR routing protocol under all scenarios. In the future, the performance of Enhanced DSR routing protocol can be analyzed under different DOS attacks to make it secure against wide range of attacks.

\section{References}

[1] N. Milanovic, M. Malek, A. Davidson,Veljko Milutinovic, Routing and security in mobile ad hoc networks, IEEE, Vol 37, Issue 2, (2004).

[2] X. Zhang, F. Zou, E. Wang, and D. Sung, Exploring the Dynamic Nature of Mobile Nodes For Predicting Route Lifetime in Mobile Ad Hoc Networks, IEEE Transaction on Vehicular Technology, Vol 59, Issue 3, (2010).

[3] H. Xu, X. Wu, H. R. Sadjadpour, and J. J. Garcia-Luna-Aceves, A Unified Analysis of Routing Protocols in MANETs, IEEE Transaction on Communications, Vol 58, Issue 3, March (2010).

[4] G. Bhatia and V. Kumar, An enhanced DSR caching scheme based on cross layer information, Communications in Computer and Information Science, Springer, (2011).

[5] U. R. Bhatt, N. Nema, R. Upadhyay, Enhanced DSR: An efficient routing protocol for MANET, IEEE, Proceedings of the 2014 International Conference on Issues and Challenges in Intelligent Computing Techniques, ICICT, (2014).

[6] B. Singh and R. Hans, TCP and UDP Based Performance Analysis of AODV,DSR and DSDV Routing Protocols Under Different Traffic Conditions in Mobile AdHoc Networks, International Journal of Future Generation Communication and Networking, Vol 8, No. 2(2015), pp. 73-92, (2015).

[7] [U. Odih, P. Bakalis and P. Rapajic, Investigating the Impact of Traffic Type on the Performance of On Demand Routing protocols and Power Consumption in MANET, Springer, Proceeding of the Second International Afro-European Conference for Industrial Advancement AECIA, Vol 427, (2016). 
[8] C. Mbarushimana and A. Shahrabi, Comparative Study of Reactive and Proactive Routing Protocols Performance in Mobile Ad Hoc Networks, (IEEE), $21^{\text {st }}$ International Conference on Advanced Information Networking and Applications Workshops, (2007).

[9] Z. Luo, F. Liu and Y. Xie, User-Perceived FTP Service QOS Parameters and Measurement, IEEE, Proceedings of IC-NIDC 2009, (2009).

[10] T. Le, G. Kuthethoor, C. Hansupichon, P. Sesha and J. Strohm, Reliable User Datagram Protocol for Airborne Network, IEEE, (2009).

[11] N. Ya'acob, N. Rosli, A. L. Yusof and M. T. Ali, Investigate the Performance Metrics of Mobile Ad Hoc Networks(MANET), IEEE Symposium on Wireless Technology and Applications (ISWTA), (2013).

[12] X. Yu, Distributed cache updating for the dynamic source routing protocol, IEEE Transactions on Mobile Computing, Vol 5, Issue 6, June (2006).

[13] L. Shrivastava, S. S.Bhadauria, G.S.Tomar, Performance Evaluation of Routing Protocols in MANET with Different Traffic Loads, 2011 International Conference on Communication Systems and Network Technologies, (2011).

I. S. Ibrahim, P. J.B. King and R. Pooley, Performance Evaluation for routing Protocols for MANET, Fourth International Conference on Systems and Networks Communications, IEEE, (2009).

[14] L Raja, Dr. S S. Baboo, Performance Analysis and Simulation of Reactive Routing Protocols (AODV, DSR and TORA) in MANET using NS-2, International Journal of Advanced Research in Computer Science and Management Studies, Vol 2, Issue 8, (2014).

\section{Authors}

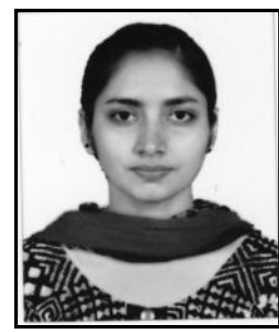

Kulwinder Kaur, student of M. Tech., Computer Science and Engineering Department, DAV University, Jalandhar, Punjab (INDIA).B. Tech. professional with specialization in Computer Science from SBBSIET (PTU), Jalandhar, Punjab (INDIA). Member of Computer Society of India.

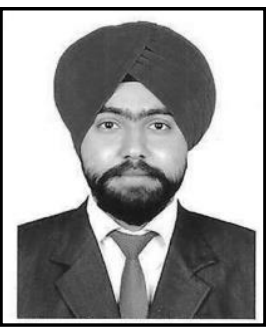

Simar Preet Singh, presently an Assistant professor at DAV University, Jalandhar is also a Microsoft Professional. Apart from this he is also having certifications like Microsoft Certified System Engineer (MCSE), Microsoft Certified Technology Specialist (MCTS) and Core Java. He has also worked with Infosys Limited for nearly two years. He has presented many research papers in various National and International Conferences in India and Abroad. His areas of interests include Network security, Big Data and Cloud Computing. 
International Journal of Future Generation Communication and Networking Online Vol. 9, No. 4, (2016) 